\title{
Nelson Samesima
}

\section{Caracterização do padrão da ativação elétrica}

\author{
ventricular de indivíduos portadores de
}

ressincronizador cardíaco através do

mapeamento eletrocardiográfico de superfície

Tese apresentada à Faculdade de Medicina da Universidade de São Paulo para obtenção de título de Doutor em Ciências

Programa de Cardiologia

Orientador: Prof.Dr. Carlos Alberto Pastore

São Paulo

2011 
Dados Internacionais de Catalogação na Publicação (CIP)

Preparada pela Biblioteca da

Faculdade de Medicina da Universidade de São Paulo

Creprodução autorizada pelo autor

Samesima, Nelson

Caracterização do padrão da ativação elétrica ventricular de indivíduos portadores de ressincronizador cardíaco através do mapeamento eletrocardiográfico de superfície / Nelson Samesima. -- São Paulo, 2011.

Tese(doutorado)--Faculdade de Medicina da Universidade de São Paulo. Programa de Cardiologia.

Orientador: Carlos Alberto Pastore.

Descritores: 1.Mapeamento potencial de superfície corporal 2.Terapia de ressincronização cardíaca 3.Insuficiência cardíaca

USP/FM/DBD-077/11 
Homenagem 
Ao prof.Dr. Carlos Alberto Pastore, amigo, parceiro, professor e orientador. Sua ajuda e apoio antes, durante e após o término da tese foram determinantes para a execução deste trabalho. Sua sensibilidade nas sugestões, nas intervenções e nos comentários sempre surgia nos momentos que mais necessitei. Durante todos estes anos de convívio, o valor dos ensinamentos que consegui absorver é inestimável. Muito obrigado pelas oportunidades. 
Dedicatória 
Aos meus pais Anna Margarida e Marcus Nelson, sempre presentes em todos os momentos de minha vida, cujo incentivo, apoio, tolerância, orientações, conselhos e infinito amor foram e são fundamentais na minha formação pessoal e profissional; Sem vocês, pouco teria evoluído e alcançado como homem e médico. Às minhas irmãs Daniela e Anna Amélia, mais próximas a cada dia, presentes nas decisões mais difíceis de minha vida, bem como nos momentos mais felizes, além do apoio incondicional ao longo dos anos; Vocês são muito importantes em minha vida.

À Mirella, amiga, companheira, minha fonte inspiradora, uma luz que surgiu em minha vida, tornando-a incomparavelmente especial. Além do apoio sentimental, suas inúmeras sugestões foram de extrema valia na elaboração desta tese. 
Agradecimentos 
Não poderia deixar de agradecer aos colegas, aos amigos e aos professores que colaboraram das mais variadas maneiras na elaboração desta tese, bem como na sua finalização, ao longo destes anos. Meu sincero obrigado a todos.

Ao Prof. Dr. Eduardo Argentino Sosa pelo respeito, admiração, ensinamentos e importantes sugestões na elaboração do trabalho.

Ao Prof. Dr. Martino Martinelli Filho pelas sugestões ao longo dos anos na realização da tese.

Ao Dr. Roberto Andrés Gomes Douglas, amigo, incentivador e colaborador na realização deste trabalho.

Ao Dr. Anísio Alexandre Andrade Pedrosa pela parceria, apoio e colaboração no trabalho. Ao Prof.Dr. Antonio Carlos Palandri Chagas, ao Prof.Dr. Maurício Ibrahim Scanavacca e ao Prof.Dr. Fernando Bacal pelas importantes sugestões que possibilitaram a qualificação desta tese.

Aos meus companheiros do Serviço de Eletrocardiologia do InCor, Dra. Nancy M. M. O. Tobias e Dr. Horácio Pereira Gomes Filho, pelo incentivo e paciência ao longo dos anos para a realização do meu trabalho.

À amiga e professora Márcia Dancini pelo profissionalismo, competência, seriedade, e incansável busca da perfeição durante todos estes anos que trabalhamos juntos. 
Às secretárias do Serviço de Eletrocardiologia do InCor, em especial da nossa equipe de Eletrocardiografia Ana Paula de La Vetta, Gisele Ferreira da Silva, Edenilza Gomes da Silva e Gisele Coelho Souza pela competência e apoio durante estes anos de elaboração de meu trabalho.

À técnica Sônia A. Belleti Nogueira pela dedicação e competência na realização dos exames.

À Enfermeira Hsia Sao Wah pela competência e companheirismo ao longo de todos os anos de trabalho juntos.

Ao Prof. Dr. Valdir Golin pelos ensinamentos e importante papel em minha formação como médico.

Ao Dr. Raul José Pádua Sartini, amigo fiel, parceiro, sempre presente nos momentos mais importantes de minha vida.

Aos amigos Marden Tebet, Christiano Cocuzza, Irineu Massaia, André Dabarian, Antonio Appezato, Rafael Munerato, Rafael Greco, Mauro Lopes e Vital Passos Jr pelo convívio solidário. 


\section{Sumário}

Lista de abreviaturas

Lista de tabelas

Lista de figuras

Lista de gráficos

Resumo

Summary

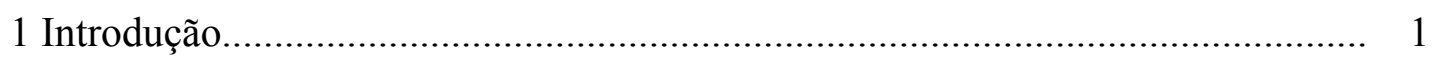

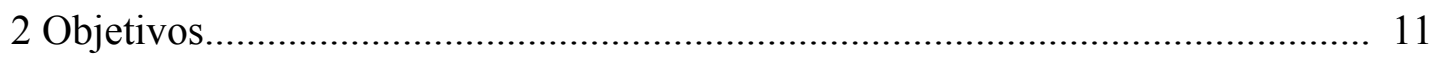

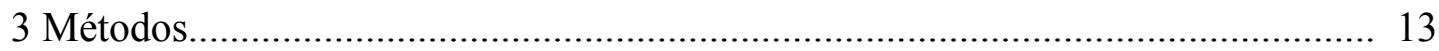

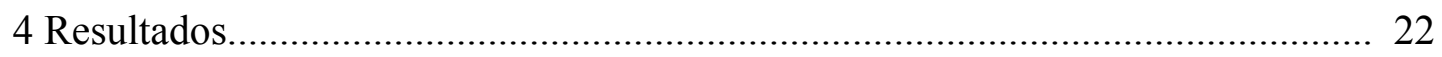

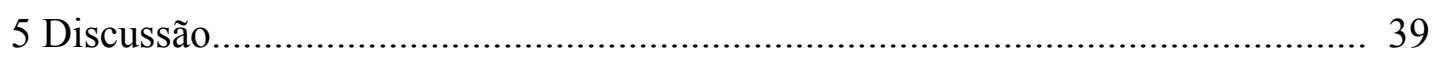

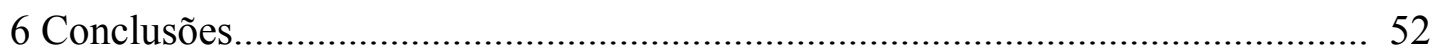

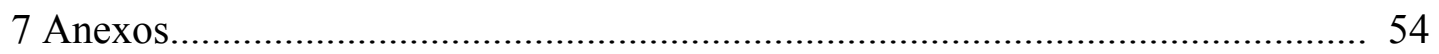

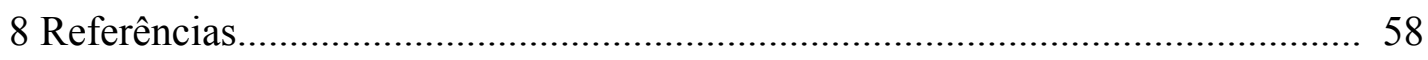




\section{LISTA DE ABREVIATURAS}

\begin{tabular}{|c|c|}
\hline $\mathrm{ACC}$ & American College of Cardiology \\
\hline AHA & American Heart Assotiation \\
\hline $\mathrm{BRD}$ & bloqueio de ramo direito \\
\hline BRE & bloqueio de ramo esquerdo \\
\hline D.P. & desvio padrão \\
\hline ECG & eletrocardiograma \\
\hline et al. & e outros \\
\hline FA & fibrilação atrial \\
\hline FEVE & fração de ejeção do ventrículo esquerdo \\
\hline I.C. & intervalo de confiança \\
\hline IECA & inibidor da enzima conversora de angiotensina \\
\hline Máx & máximo \\
\hline MES & mapeamento eletrocardiográfico de superfície \\
\hline Mín & mínimo \\
\hline $\mathrm{ms}$ & milissegundos \\
\hline ns & não significativo \\
\hline
\end{tabular}


NYHA

RR

RS

S

TAV

TRC

VCG

VAT MAP

VD

VE
New York Heart Assotiation

risco relativo

ritmo sinusal

septo

tempo de ativação ventricular

terapia de ressincronização cardíaca

vetorcardiograma

ventricular activation time mapping

ventrículo direito

ventrículo esquerdo 


\section{LISTA DE TABELAS}

Tabela 1 - Ativação elétrica ventricular durante ritmo próprio (valores em milissegundos)

Tabela 2 - Ativação elétrica ventricular durante estimulação biventricular (valores em milissegundos)

Tabela 3 - Comportamento da ativação elétrica ventricular (valores em

milissegundos)

Tabela 4 - Delta TAV - Diferença entre os TAV's da estimulação biventricular e o

ritmo sinusal + BRE. 35 


\section{LISTA DE FIGURAS}

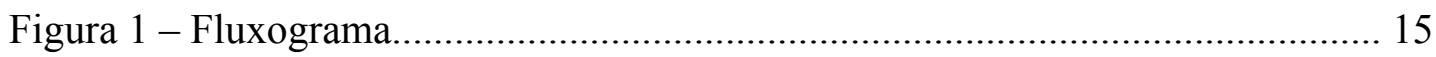

Figura 2 - Distribuição das 87 derivações no tórax anterior e posterior..................... 15

Figura 3 - Mapa de linhas isócronas fornecido pelo MES.................................... 17

Figura 4 - Matriz com os valores dos tempos de ativação ventricular obtida pelo

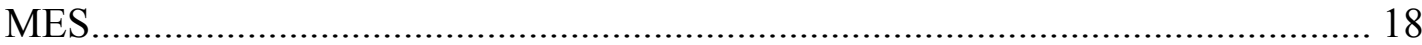

Figura 5 - Regionalização dos tempos de ativação ventricular............................... 19

Figura 6 - Mapa de linhas isócronas durante ritmo sinusal e BRE....................... 27

Figura 7 - Mapa de linhas isócronas durante estimulação biventricular.................. 31 


\section{LISTA DE GRÁFICOS}

Gráfico 1: TAV Global Máximo e Médio durante ritmo sinusal e BRE.

Gráfico 2: TAV Regional do VD, do Septo e do VE durante ritmo sinusal e BRE. 25

Gráfico 3: TAV Inter Regional VE-VD, Septo-VD e Septo-VE durante ritmo sinusal e BRE.. 25

Gráfico 4: TAV Global Máximo e Médio durante estimulação biventricular. 29

Gráfico 5: TAV Regional do VD, do Septo e do VE durante estimulação biventricular. 29

Gráfico 6: TAV Inter Regional VE-VD, Septo-VD e Septo-VE durante estimulação biventricular. 29

Gráfico 7: TAV Global Máximo. 32

Gráfico 8: TAV Global Médio. 33

Gráfico 9: TAV Regional do VD, do Septo e do VE. 33

Gráfico 10: TAV Inter Regional VE-VD, Septo-VD e Septo-VE 33

Gráfico 11: Delta TAV Global Médio 36

Gráfico 12: Delta TAV Regional do VD, do Septo e do VE. 36

Gráfico 13: Delta TAV Inter Regional VE-VD, Septo-VD e Septo-VE. 36 
Resumo 
Samesima, N. Caracterização do padrão da ativação elétrica ventricular de indivíduos portadores de ressincronizador cardíaco através do Mapeamento eletrocardiográfico de superfície. [tese]. São Paulo: Faculdade de Medicina, Universidade de São Paulo; 2011.

INTRODUÇÃO: Os benefícios na morbi-mortalidade obtidos pela terapia de ressincronização cardíaca (TRC) em pacientes com insuficiência cardíaca estão bem estabelecidos. Métodos invasivos e não invasivos têm sido utilizados para identificar aqueles que realmente se beneficiarão da TRC, mas 30\% destes pacientes não apresentam melhora clínica/funcional. Poucos estudos avaliaram o comportamento elétrico dos pacientes submetidos à TRC.

OBJETIVO: Utilizamos um método não invasivo, o mapeamento eletrocardiográfico de superfície (MES) para caracterizar o padrão da ativação elétrica ventricular em pacientes após a TRC.

MÉTODOS: Estudamos 91 pacientes submetidos à TRC, com insuficiência cardíaca e bloqueio de ramo esquerdo (BRE), sendo 36 excluídos devido a FA (20), BRD (3), cardiopatias hipertrófica (3) e congênita (1) ou dependentes de marcapasso antes da TRC (9). Idade média: $61 \pm 10$ anos, FEVE:0,28 $\pm 0,9$, QRS:182 $\pm 24 \mathrm{ms,} \mathrm{classe} \mathrm{funcional} \mathrm{NYHA:}$ III(78\%) e IV(22\%). Com o ressincronizador ligado e desligado, todos realizaram o MES, o qual fornece 87 derivações simultâneas (58 anteriores e 29 posteriores). Os mapas isócronos obtidos pelo MES forneceram os tempos de ativação ventricular (TAV) global máximo e médio nas 87 derivações. Os TAV's obtidos foram regionalizados, sendo calculados os valores médios nas áreas do VD, do septo e do VE. Analisamos a diferença do TAV entre o VD e o VE, entre o septo e o VD e entre o septo e o VE, definidos como TAV InterRegional. Utilizados os testes de Mann-Whitney, Kruskall-Wallis, Fisher. Nível de significância: $P \leq 0.05$.

RESULTADOS: O MES durante ritmo sinusal e BRE mostrou que os pacientes apresentavam prolongado TAV Global máximo e médio ( $138 \mathrm{~ms}$ e $64,8 \mathrm{~ms}$, respectivamente) com significativa diferença Regional $(54,5$ x 56,4 x 95,9ms; $<<0,0001$; VD, septo e VE, respectivamente). A TRC reduziu o TAV Global máximo (138ms x $131 \mathrm{~ms} ; \mathrm{p}=0,007)$ e o TAV Regional do VE $(95,9$ x 77,3ms; $\mathrm{p}=0,001)$. Houve aumento do TAV Regional do VD $(54,5 \times 78,9 \mathrm{~ms} ; \mathrm{p}=0,001)$, sem alteração do TAV Regional do septo $(56,4 \times 59,6 \mathrm{~ms} ; \mathrm{p}=\mathrm{ns})$. O comportamento do TAV Inter-Regional foi: Redução do TAV VE-VD $(43,8$ x 17,0ms; $\mathrm{p}=0,001)$ e do TAV septo-VE $(42,6 \times 16,3 \mathrm{~ms} ; \mathrm{p}=0,001)$ e aumento do TAV septo-VD $(6,9 \times$ $16,0 \mathrm{~ms} ; \mathrm{p}=0,002)$.

CONCLUSÃO: O Mapeamento Eletrocardiográfico de Superfície possibilitou a caracterização detalhada da ativação elétrica ventricular de pacientes portadores de ressincronizador cardíaco através do comportamento elétrico global, regional e InterRegional durante ritmo sinusal com bloqueio de ramo esquerdo e estimulação biventricular.

Descritores: Mapeamento potencial de superfície corporal; Terapia de ressincronização cardíaca; insuficiência cardíaca. 
Summary 
Samesima N. Body surface potential mapping characterization of the ventricular electrical activation pattern of individuals with cardiac resynchronization device [thesis] São Paulo: "Faculdade de Medicina, Universidade de São Paulo"; 2011.

INTRODUCTION: The benefits of lower morbidity and mortality obtained with cardiac resynchronization therapy (CRT) in patients with heart failure are already well established. Invasive and noninvasive methods have been used to identify those who will really benefit from CRT, however $30 \%$ of these patients do not improve clinically/functionally. Few studies evaluated the cardiac electrical development of patients undergoing CRT.

OBJECTIVE: To obtain through the body surface potential mapping (BSPM), a noninvasive approach, characterization of the ventricular electrical activation development in patients after CRT.

METHODS: We studied 91 patients with heart failure and left bundle-branch block (LBBB) who underwent CRT, 36 of whom were excluded for AF (20), RBBB (3), hypertrophic (3) or congenital (1) cardiomyopathy, or depended upon a pacemaker before CRT (9). Mean age was $61 \pm 10$ years, LVEF $0.28 \pm 0.9$, QRSd $182 \pm 24 \mathrm{~ms}$, NYHA functional class III(78\%) and IV(22\%). All underwent BSPM examination of 87 simultaneous leads (58 on the anterior chest, 29 on the back) with the resynchronization device on, then in intrinsic rhythm and LBBB (device off). The BSPM isochronal maps provided maximal and mean global ventricular activation times (VAT) for all the 87 leads. From VATs thus obtained, separate mean values for the RV, septum and LV areas were then calculated. VAT differences between RVLV, septum-RV and septum-LV, were analyzed and denominated inter-regional VATs. Mann-Whitney, Kruskall-Wallis and Fisher statistics were used, with $\mathrm{P} \leq .05$ established as the significance level.

RESULTS: During sinus rhythm/LBBB the BSPM showed patients evidencing prolonged maximal and mean global VATs $(138 \mathrm{~ms}$ and $64.8 \mathrm{~ms}$, respectively), with significant regional differences (54.5 vs 56.4 vs $95.9 \mathrm{~ms}$; RV, septum and LV, respectively; $\mathrm{p}<0.0001)$. CRT reduced the maximal global VAT $(138 \mathrm{~ms}$ vs $131 \mathrm{~ms}$; $\mathrm{p}=0.007)$ and the LV regional VAT $(95.9$ vs $77.3 \mathrm{~ms} ; \mathrm{p}=0.001)$. The RV regional VAT increased $(54.5 \mathrm{vs} 78.9 \mathrm{~ms} ; \mathrm{p}=0.001)$, with no alteration of the septum regional VAT (56.4 vs $59.6 \mathrm{~ms} ; \mathrm{p}=\mathrm{ns}$ ). The inter-regional VAT developed as follows: decrease in $\mathrm{VAT}_{\mathbf{L V}-\mathbf{R V}}(43.8$ vs $17.0 \mathrm{~ms} ; \mathrm{p}=0.001)$ and $\mathrm{VAT}_{\text {septum-LV }}(42.6$ vs $16.3 \mathrm{~ms}$; $\mathrm{p}=0.001)$, and increase in $\mathrm{VAT}_{\text {septum-RV }}(6.9 \mathrm{vs} 16.0 \mathrm{~ms} ; \mathrm{p}=0.002)$.

CONCLUSION: The body surface potential mapping permitted a detailed characterization of the ventricular electrical activation of patients carrying a cardiac resynchronization device, by mapping the global, regional and inter-regional electrical activation development during sinus rhythm with left bundle-branch block, and in biventricular pacing.

Descriptors: Body surface potential mapping; Cardiac resynchronization therapy; heart failure. 
Capítulo I 


\section{Introdução:}

A insuficiência cardíaca tornou-se um dos principais problemas de saúde pública em todo o mundo. Os grandes estudos mostram o aumento de sua incidência nos últimos 60 anos, sendo atribuído importante papel à hipertensão arterial sistêmica, à doença coronariana, ao diabetes mellitus e à doença valvar como fatores de maior risco para o desenvolvimento da insuficiência cardíaca, como mostram Kannel et al. (1991 e 2000), Ho et al. em duas publicações em 1993, Levy et al. (2002) e Roger et al. (2004), Barker et al. (2006), além de uma revisão feita por Villacorta et al. em 1999. Estes mesmos estudos também mostram uma significativa correlação entre o aumento da idade e da incidência de insuficiência cardíaca, além de constatarem elevados índices de mortalidade em ambos os sexos. Ferreira SM et al. (2010) mostram a anemia e a insuficiência renal como fatores preditores de pior evolução da insuficiência cardíaca na população brasileira. Outro dado importante, demonstrado por Kannel et al. (1991) e Ho et al. (1993b), foi o drástico crescimento do número de internações hospitalares por insuficiência cardíaca, justificado tanto pelo aumento da população idosa quanto pelo prolongamento da sobrevida de pacientes cardíacos propiciado pelas terapias que surgiram ao longo dos anos, de acordo com resultados de Armstrong et al. (1993), Garg e Yusuf (1995) e Foody et al. (2002). No Brasil, os estudos medicamentosos com o IECA, com o milrinone, com diurético e com betabloqueador no tratamento da insuficiência cardíaca, publicados por Ferreira Filho et al. (1992), Gun et al. (1995), Eterno et al. (1998), Chizzola et al. (2000) e Issa VS et al. (2010), apresentaram desfechos semelhantes. Por outro lado, Ho et al. (1993a) e Levy et al. 
(2002) mostram uma redução da mortalidade destes pacientes, quando comparam as décadas de 50 a 90, concordantes com as publicações de Roger et al. (2004) e Barker et al. (2006).

Dentre as opções terapêuticas não farmacológicas para a insuficiência cardíaca, a estimulação artificial de ambos os ventrículos tem sido bastante estudada nos últimos dez anos. Este tratamento surgiu da observação de pacientes portadores de insuficiência cardíaca associada a bloqueio de ramo esquerdo que evoluíam com piora do quadro, decorrente de uma deterioração da função sistólica, como evidenciado por Leclercq et al. em 2002 e 2004 e Auricchio et al. em 2004a. Em teoria, a presença do bloqueio de ramo esquerdo denota um transtorno elétrico da condução cardíaca, em que se observa inicialmente a ativação do ventrículo direito e, após um grande retardo, a ativação do ventrículo esquerdo. Dessa maneira, o método denominado de terapia de ressincronização cardíaca (TRC) tem como objetivo promover a ressincronização ventricular nos pacientes que apresentam um retardo da condução elétrica interventricular, como demonstraram Cazeau et al. (2001), Abraham et al. em 2002 e 2003, Leclercq et al. (2002 e 2004), Bax et al. em 2003, Auricchio et al. em 2004a, Jarcho (2005), Daubert et al. (2006), Dickstein et al. (2009) e Merkely et al. em 2010. Os estudos multicêntricos que avaliaram os resultados da TRC mostram significativa melhora da qualidade de vida, bem como uma redução da mortalidade dos pacientes submetidos ao implante do ressincronizador, de acordo com Bakker et al. (2000), Bradley et al. (2003), St John Sutton et al. (2003), Bristow et al. (2004), Cleland et al. (2005), Donal et al. (2006), Piccini et al. (2008), Moss et al. (2009) e, Ypenburg et al., também em 2009. A partir 
destes resultados, pacientes com insuficiência cardíaca, em ritmo sinusal, com fração de ejeção do ventrículo esquerdo menor ou igual a 35\%, evidências de dissincronia do ventrículo esquerdo, com sintomas moderados a graves (classe funcional NYHA III ou IV) e tratamento farmacológico otimizado são candidatos à terapia de ressincronização cardíaca, de acordo com o Consenso da ACC/AHA (Hunt et al. em 2005), a European Society of Cardiology/European Heart Rhythm Association (Vardas et al. em 2007) e as Diretrizes Brasileiras de Dispositivos Cardíacos Eletrônicos Implantáveis (Martinelli Filho et al. em 2007).

Os consensos americano e europeu, assim como o brasileiro, também se embasaram na publicação desses resultados, analisados pelas meta-análises. Há pelo menos seis meta-análises, no período entre 2003 e 2010, que confirmam os bons resultados da terapia de ressincronização cardíaca relacionados aos desfechos de morbidade e de mortalidade, envolvendo os grandes estudos. Estas foram compostas de quatro a nove estudos, as quais continham entre 1.634 a 4.531 pacientes. As publicações de Bradley et al. (2003), de Rivero-Ayerza M et al. (2006) e de McAlister et al. (2007) são contundentes na afirmação de que a TRC reduz a mortalidade e os sintomas de insuficiência cardíaca. Já os trabalhos de Rossi et al. (2008) e de Huang et al. (2010) concluem que a TRC tem um impacto positivo na redução da mortalidade total. No Brasil, em 2009, Lemos Júnior e Atallah mostram em sua meta-análise que a terapia de ressincronização cardíaca reduz significativamente o risco de hospitalização por insuficiência cardíaca. Apesar dos resultados acima descritos serem consistentes e claramente reprodutíveis, são observados entre $20 \%$ a $30 \%$ de pacientes que não apresentam melhora 
clínica/funcional após o implante do ressincronizador, comportamento que se repete em todos os estudos. Estes pacientes são denominados NÃO RESPONDEDORES e são bem descritos por Leclercq e Kass (2002), Abraham e Hayes (2003), Saxon e Ellenbogen (2003) e em duas publicações de Bax et al. em 2004. Por esse motivo, inúmeros trabalhos invasivos e não invasivos foram feitos com o objetivo de encontrar parâmetros clínicos/laboratoriais que melhor indicassem a TRC, reduzindo, assim, as taxas de não respondedores.

$\mathrm{Na}$ literatura, encontramos fundamentalmente estudos que analisaram características eletrocardiográficas e, principalmente, os que investigaram diversos parâmetros ecocardiográficos, ambos considerados não invasivos. No primeiro, foram avaliadas a duração do complexo QRS basal, sua redução após a TRC e a presença de bloqueio de ramo esquerdo e bloqueio de ramo direito. Os resultados são praticamente unânimes em afirmar que tanto a duração do QRS antes do implante do ressincronizador quanto a presença de BRD não se mostraram fatores de melhor evolução clínica, como descritos por Pitzalis et al. (2002), Reynolds et al. (2004), Molhoek et al. (2004), Adelstein et al. (2009), Gervais et al. (2009). Nos estudos de Molhoek et al. (2004) e de Lecoq et al. (2005), o encurtamento da duração do complexo QRS após a TRC foi fator preditor de melhora clínica/funcional. Um elegante trabalho de Kashani e Barold (2005) faz uma abrangente avaliação do papel do eletrocardiograma na ressincronização cardíaca e conclui que não há parâmetros eletrocardiográficos que diferenciem os pacientes respondedores dos não respondedores. 
Já entre aqueles que utilizaram o ecocardiograma para estudar a TRC, percebemos resultados inicialmente bastante promissores no reconhecimento dos respondedores, como sugerem Bax et al. em 2004a,b e Silva e Barretto em 2005. Dentre os parâmetros estudados, os principais estão relacionados ao doppler tecidual e à presença de dissincronia do ventrículo esquerdo, aos dados sobre o volume diastólico final do VE, ao índice de dissincronia sistólica, à avaliação do retardo elétrico septo-parede posterior e até à utilização do ecocardiograma para guiar a colocação do eletrodo no ventrículo esquerdo, como descritos por Stellbrink et al. (2001), Pitzalis et al. (2002), Bax et al. (2003, 2004a,b), Yu et al. (2003 e 2005), Murphy et al. (2006) e Bleeker et al. (2007). No entanto, também em 2006, Hawkins et al. apresentaram um excelente artigo de revisão sobre como a avaliação das dissincronias elétrica e mecânica estava sendo realizada nos estudos até então publicados, bem como o significado destes resultados. Esses autores verificaram que os estudos eram poucos e pequenos, observacionais, não randomizados e oriundos de centros únicos e de curta duração, em sua maioria. Eles concluíram que as atuais diretrizes relacionadas à indicação da TRC não deveriam ser modificadas para a inclusão do ecocardiograma e sugeriram a realização de um estudo prospectivo e controlado sobre o papel do ecocardiograma na terapia de ressincronização cardíaca.

Logo depois, em 2008, Chung et al. publicaram o estudo PROSPECT, que envolveu 53 centros na Europa, Hong Kong e Estados Unidos, contendo 498 pacientes. Foram analisados doze parâmetros ecocardiográficos de dissincronia (convencional e doppler tecidual), após treinamento na aquisição dos dados e de 
maneira cega à informação clínica. Concluíram que, dada a modesta sensibilidade e especificidade de todos os parâmetros avaliados, nenhuma medida ecocardiográfica de dissincronia poderia ser recomendada na seleção de pacientes para a terapia de ressincronização cardíaca.

Dentre os estudos invasivos relacionados à TRC, temos o trabalho de Pratola et al. (2010) que utilizou o estudo eletrofisiológico e o mapeamento eletroanatômico para analisar os tempos de ativação ventricular total, mais precoces e mais tardios, comparar com parâmetros hemodinâmicos e correlacionar com a ativação elétrica ventricular durante o ritmo sinusal e durante diversas formas de estimulação (VD, vários locais do VE e estimulação biventricular). Este foi um estudo pequeno (9 pacientes) que mostrou uma grande variabilidade nos parâmetros elétricos e hemodinâmicos.

Outros estudos invasivos utilizaram as informações periprocedimento, isto é, informações dos eletrodos ventriculares (durante e após o implante do ressincronizador) e correlacionaram os dados elétricos com os hemodinâmicos, bem como com a evolução clínica. Em 2006, Singh et al. mostraram que um retardo elétrico do eletrodo do VE abaixo de $50 \%$ da duração do complexo QRS poderia ser um indicador de pior resposta hemodinâmica e evolução clínica a longo prazo, em pacientes com cardiomiopatia não isquêmica. Já Van Gelder et al. (2008) compararam duas maneiras de se definir o melhor intervalo V-V (cálculo automático do aparelho ou guiado por medidas hemodinâmicas invasivas) após o implante do ressincronizador, porém não demonstraram haver superioridade de 
uma em relação a outra. Finalmente, em publicação recente (2010), Sassone et al. apresentaram resultados muito interessantes a respeito de uma medida denominada de retardo elétrico intereletrodo VD-VE, realizada em 52 pacientes submetidos à TRC. Esta medida é a diferença de tempo entre os eletrogramas intracavitários obtidos a partir do eletrodo do ventrículo direito em relação ao do ventrículo esquerdo, ao final do implante do ressincronizador. 0 pacientes considerados respondedores (redução do volume sistólico final do VE maior ou igual a 15\%, após 6 meses) apresentavam um retardo elétrico intereletrodo VD-VE significativamente menor em relação aos não respondedores $(22,1 \mathrm{~ms} \pm 18,4 \mathrm{~ms} x$ 43,6 ms $\pm 15,0 \mathrm{~ms})$. Essa medida foi a única variável independente preditora de boa resposta à TRC.

Concomitantemente, o interesse pelo comportamento elétrico ventricular tem sido crescente e publicações que utilizaram diferentes métodos (Pastore et al. em 1996, Rodriguez et al. em 2003, Peichl et al. em 2004, Auricchio et al. em 2004b, Fantoni et al. em 2005), em indivíduos portadores de bloqueio de ramo esquerdo e ramo direito proporcionaram um melhor entendimento do fenômeno elétrico cardíaco. Medvegy et al. (2002) fez um belo resumo do Mapeamento Eletrocardiográfico de Superfície (MES), bem como das possibilidades atuais de sua utilização. Este método se apresenta como uma alternativa não invasiva já consagrada pelos estudos dos fenômenos elétricos dos ventrículos em indivíduos normais, com bloqueio de ramo esquerdo e pelos estudos iniciais em portadores de ressincronizador cardíaco (Pastore et al. em 1996, 2006 e 2007, Varma et al. em 2007), e possibilita a análise da ativação elétrica cardíaca de modos distintos, 
conseguindo detalhar espacialmente tanto os componentes elétricos unipolares quanto o componente bipolar. O MES tem sido amplamente utilizado desde o início dos anos 90 como linha de pesquisa do Serviço de Eletrocardiologia do InCor. Nestes vinte anos, foram realizados estudos com o mapeamento eletrocardiográfico de superfície em portadores de insuficiência coronariana como no infarto agudo do miocárdio de parede inferior, no infarto do ventrículo direito e com aneurisma do ventrículo esquerdo (Pastore et al. em 1991, 1995 e 1997, respectivamente), em indivíduos com hipertensão arterial sistêmica maligna (Bortolotto et al. em 1992), em pacientes submetidos à ablação de vias anômalas (Pastore e Moffa em 1993) e em portadores de BRE (Pastore et al. em 1996). A partir do ano de 2000, estudou-se a dispersão da onda P em idosos (Szlejf et al. em 2002), iniciou-se o estudo do comportamento da repolarização ventricular de indivíduos idosos com insuficiência cardíaca (Carvalho et al. em 2005), de pacientes submetidos à cirurgia de ventriculectomia (Pastore et al. em 2004) e em portadores de distrofia muscular miotônica (Pastore et al. em 2002a). Também foi demonstrada a utilidade do MES na identificação de indivíduos portadores de Síndrome de Brugada com ECG normal de 12 derivações (Samesima et al. em 2003).

Em 2002b, Pastore et al. publicaram o primeiro estudo que envolveu o MES e pacientes submetidos à terapia de ressincronização cardíaca, dando início a esta promissora linha de pesquisa. Um maior detalhamento de todos estes estudos com o mapeamento eletrocardiográfico de superfície pode ser encontrado nas publicações do Serviço de Eletrocardiologia do InCor, ao longo destas duas décadas (Pastore e Moffa em 1992, Moffa et al. em 1994, Pastore em 2000, 2001 e 2011). 
Desta forma, a avaliação pormenorizada da ativação ventricular pode fornecer importantes informações sobre o comportamento elétrico cardíaco, possibilitando uma melhor caracterização do sincronismo entre os ventrículos direito e esquerdo.

Como podemos observar, a despeito dos vários trabalhos envolvendo pacientes portadores de ressincronizador cardíaco, a busca por um método simples, rápido, de fácil execução, com baixo risco ao paciente, reprodutível e de elevada acurácia para determinar aqueles indivíduos que melhor responderão à TRC ainda está longe de terminar. Assim, nosso estudo teve como objetivo utilizar um método não invasivo, o mapeamento eletrocardiográfico de superfície (MES), para analisar e caracterizar o comportamento da ativação elétrica ventricular de pacientes submetidos à terapia de ressincronização cardíaca. 
Capítulo II

Objetivos 
O estudo teve como objetivo utilizar um método não invasivo, o mapeamento eletrocardiográfico de superfície, para analisar e caracterizar o comportamento da ativação elétrica ventricular de pacientes submetidos à terapia de ressincronização cardíaca. 
Capítulo III

Material e métodos 
Material e método:

População:

Critérios de inclusão:

Foram selecionados pacientes portadores de ressincronizador cardíaco que vinham em acompanhamento na Unidade de Estimulação Cardíaca Artificial do InCor. Todos eles com indicação clássica de terapia de ressincronização cardíaca, ou seja, apresentavam previamente ao implante ritmo sinusal e bloqueio de ramo esquerdo ao eletrocardiograma, baixa fração de ejeção do ventrículo esquerdo, estavam em uso regular de medicações para insuficiência cardíaca e encontravamse em classe funcional III/IV da NYHA (Anexo A).

\section{Critérios de exclusão:}

Pacientes com fibrilação atrial e/ou dependentes de marcapasso definitivo antes do implante do ressincronizador e/ou portadores de bloqueio de ramo direito e/ou com diagnóstico de cardiopatia hipertrófica e/ou cardiopatia congênita.

De acordo com o fluxograma abaixo (figura 1), inicialmente, noventa e um pacientes submetidos à terapia de ressincronização cardíaca (TRC), realizaram o mapeamento eletrocardiográfico de superfície (MES). Destes, trinta e seis foram excluídos, sendo vinte pacientes com fibrilação atrial, nove pacientes portadores de marcapasso definitivo, três pacientes com cardiopatia hipertrófica, três pacientes com bloqueio de ramo direito, um paciente com cardiopatia congênita. 


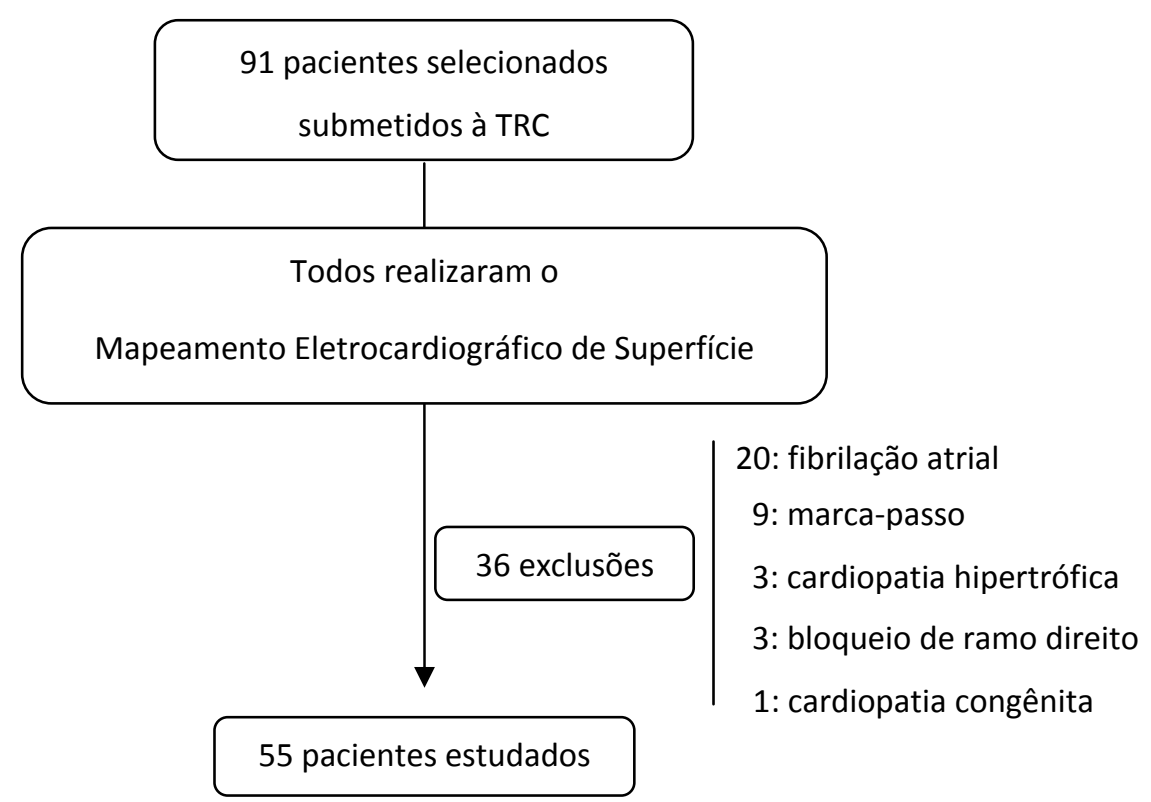

Figura 1: Fluxograma.

\section{Mapeamento eletrocardiográfico de superfície:}

O mapeamento eletrocardiográfico de superfície (MES) é um método não invasivo realizado pelo equipamento Fukuda Denshi 7100 (Inc, Tókio, Japão) através da análise de oitenta e sete derivações eletrocardiográficas simultâneas posicionadas na face anterior (58) e posterior (29) do tórax (figura 2).

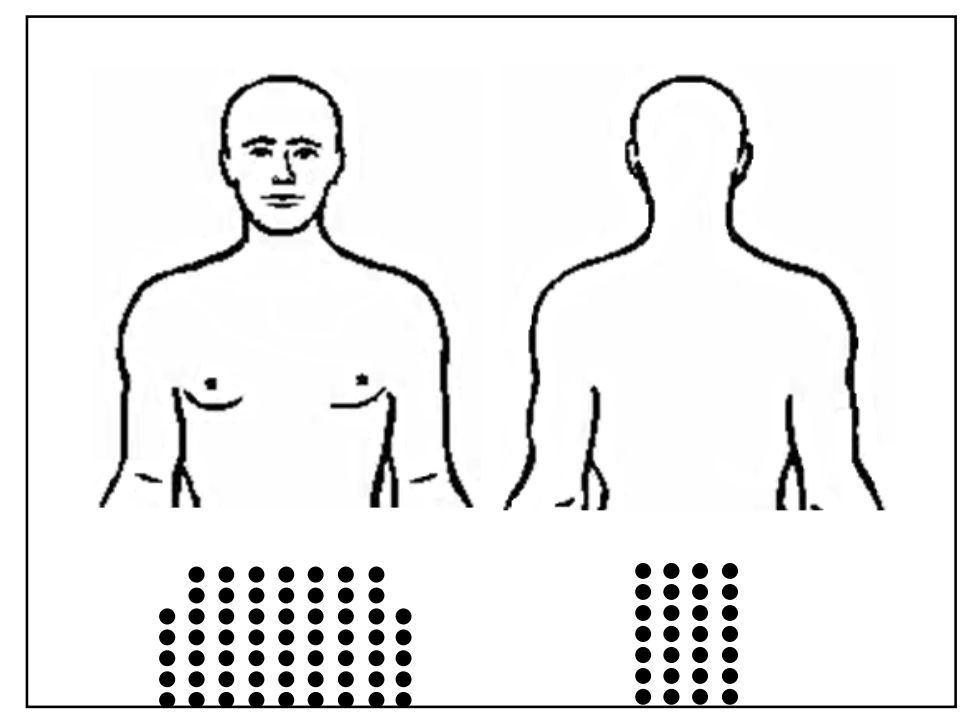

Figura 2: Distribuição das 87 derivações no tórax anterior e posterior. 
O MES possibilita a análise da ativação elétrica cardíaca de modos distintos e consegue detalhar espacialmente os componentes elétricos unipolares, bem como o componente bipolar. Além do eletrocardiograma de oitenta e sete derivações, do vetorcardiograma e dos mapas isopotenciais, esse método permite o estudo do mapa das linhas isócronas. A força diagnóstica dos vários tipos de mapas eletrocardiográficos de superfície tem sido bem superior à do ECG tradicional de 12 derivações, para grande parte dos distúrbios do coração. Os aperfeiçoamentos da técnica do MES possibilitaram a ampliação do diagnóstico através dos métodos gráficos convencionais (ECG, VCG e outros), o que incrementou sua aplicação na clínica cardiológica.

Para o presente estudo, utilizamos o mapa das linhas isócronas para a caracterização do comportamento da ativação elétrica ventricular na população descrita.

Como o próprio nome diz, as linhas isócronas são linhas que mostram tempos idênticos durante a ocorrência de um fenômeno elétrico. O software possibilita a caracterização da velocidade, da sequência e do momento em que a ativação elétrica ocorre nas diferentes regiões do miocárdio, que são descritos a seguir.

A velocidade da ativação elétrica cardíaca é caracterizada pelo espaçamento entre as linhas isócronas. Quanto mais próximas essas linhas, mais lenta é a propagação do estímulo elétrico, já quando a velocidade de condução é mais rápida, as linhas ficam mais afastadas entre si, como exemplificado na figura 3. 
A sequência da ativação elétrica é caracterizada pelas cores verde, amarela e vermelha, aplicadas às linhas. A área do miocárdio com ativação elétrica mais precoce recebe a cor verde, as intermediárias recebem a cor amarela, e aquelas com ativação mais tardia, a cor vermelha. Dessa forma, é possível a visualização da direção em que ocorre o fenômeno elétrico no miocárdio (figura 3).

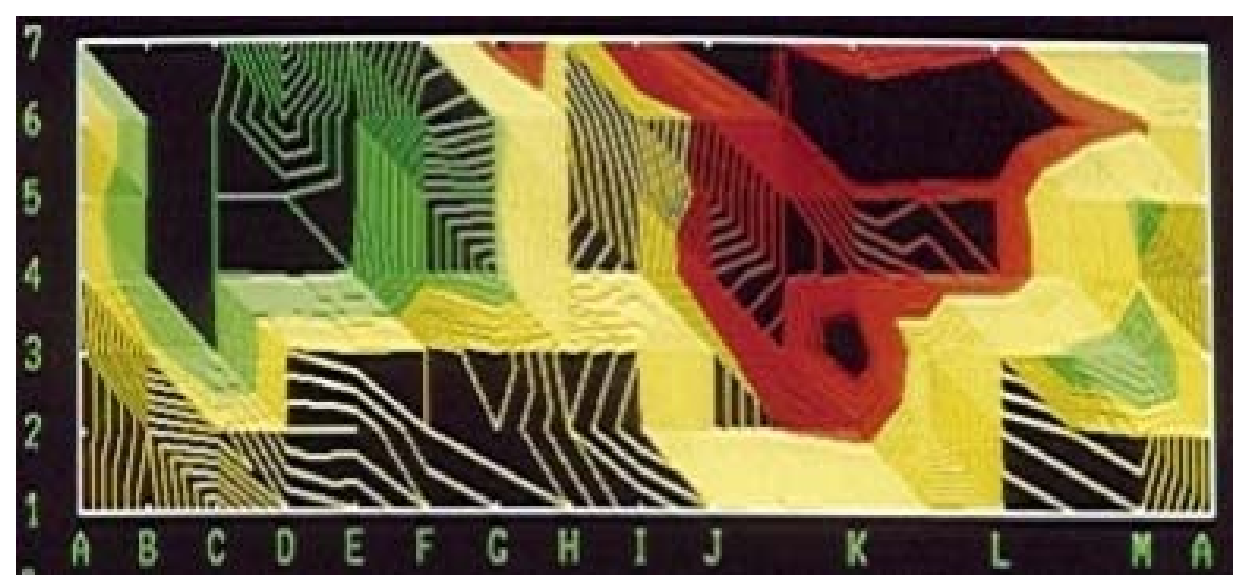

Figura 3: Mapa de linhas isócronas fornecido pelo MES - Ritmo sinusal normal.

Tanto a velocidade quanto a sequência da ativação elétrica descrevem de maneira qualitativa o fenômeno elétrico cardíaco. Entretanto, o mapa de linhas isócronas fornece ainda dados quantitativos ao final da aquisição do processo gráfico referentes ao tempo decorrido para a ocorrência do fenômeno elétrico em cada uma das 87 derivações. Como o método utiliza o complexo QRS para a análise, estes tempos estão relacionados à ativação elétrica cardíaca ventricular. Assim, o método fornece uma matriz que contém valores, em milissegundos, denominados de Tempo de Ativação Ventricular (TAV) ou VAT MAP em cada um dos oitenta e sete pontos colocados no tórax do paciente, determinando, de maneira quantitativa 
o tempo para ocorrência da ativação ventricular distribuídos espacialmente no tórax (figura 4).

\begin{tabular}{|llllllllllllll|}
\hline & A & B & C & D & E & F & G & H & I & J & K & L & M \\
$\mathbf{7}$ & & 33 & 36 & 35 & 34 & 34 & 34 & 36 & & 64 & 63 & 25 & 21 \\
$\mathbf{6}$ & & 36 & 37 & 38 & 34 & 36 & 37 & 56 & & 61 & 57 & 22 & 30 \\
$\mathbf{5}$ & 28 & 31 & 39 & 37 & 38 & 38 & 59 & 61 & 61 & 58 & 63 & 25 & 25 \\
$\mathbf{4}$ & 12 & 41 & 38 & 38 & 37 & 60 & 59 & 59 & 58 & 60 & 69 & 23 & 28 \\
$\mathbf{3}$ & 52 & 47 & 44 & 42 & 41 & 59 & 60 & 57 & 57 & 56 & 64 & 12 & 23 \\
$\mathbf{2}$ & 51 & 53 & 45 & 46 & 49 & 59 & 59 & 55 & 56 & 58 & 55 & 11 & $\mathbf{8}$ \\
$\mathbf{1}$ & 50 & 50 & 48 & 47 & 48 & 55 & 56 & 56 & 58 & 55 & 55 & 49 & 4 \\
\hline
\end{tabular}

Figura 4: Matriz com os valores dos tempos de ativação ventricular obtida pelo MES.

A análise da sequência dos tempos de ativação ventricular nas oitenta e sete derivações possibilita a caracterização do comportamento da ativação elétrica ventricular de um indivíduo submetido ao mapeamento eletrocardiográfico de superfície. Esta análise inicia-se com o denominado TAV GLOBAL, cujo dado fornece o valor do TAV Global Máximo (maior valor obtido nas 87 derivações) e TAV Global Médio (média aritmética dos TAV's nas 87 derivações).

A partir dos resultados de Medvegy et al. (2002), extraímos as informações iniciais para correlacionar a matriz dos valores dos TAV's do complexo QRS no MES com as áreas correspondentes ao ventrículo direito, à região septal e ao ventrículo esquerdo, através de uma análise estatística (Pastore et al., 2006 e 2007). Desta forma, conseguimos definir o que denominamos de TEMPO DE ATIVAÇÃo VENTRICULAR REGIONAL (TAV REGIONAL). Assim, os TAV's das derivações A, B, C, D (1 a 7) correspondem à região do ventrículo direito (VD), os TAV's das derivações E, F, G, H (1 a 7) correspondem à região do SEPTO e os TAV's das derivações I, J, K, L 
correspondem à região do ventrículo esquerdo (VE), como exemplificado na figura 5.

\begin{tabular}{|c|c|c|c|c|c|c|c|c|c|c|c|c|c|}
\hline & A & B & C & D & $\mathbf{E}$ & $F$ & G & H & I & $\mathbf{J}$ & $\mathbf{K}$ & L & M \\
\hline 7 & & 33 & 36 & 35 & 34 & 34 & 34 & 36 & & 64 & 63 & 25 & 21 \\
\hline 6 & & 36 & 37 & 38 & 34 & 36 & 37 & 56 & & 61 & 57 & 22 & 30 \\
\hline 5 & 28 & 31 & 39 & 37 & 38 & 37 & 59 & 61 & 61 & 58 & 63 & 25 & 25 \\
\hline 4 & 12 & 41 & 38 & 38 & 37 & 60 & 59 & 59 & 58 & 60 & 65 & 23 & 23 \\
\hline 3 & 52 & 47 & 44 & 42 & 41 & 59 & 60 & 57 & 57 & 56 & 64 & 12 & 23 \\
\hline 2 & 51 & 53 & 45 & 46 & 49 & 59 & 59 & 55 & 56 & 58 & 55 & 11 & 12 \\
\hline \multirow[t]{2}{*}{1} & 50 & 50 & 48 & 47 & 48 & 55 & 56 & 56 & 58 & 55 & 55 & 50 & 49 \\
\hline & A & B & C & D & E & $F$ & $\mathbf{G}$ & $\mathbf{H}$ & I & $\mathbf{J}$ & $\mathbf{K}$ & L & $\mathbf{M}$ \\
\hline \multicolumn{4}{|c|}{ VD } & & & \multicolumn{2}{|c|}{ Septo } & \multicolumn{4}{|c|}{ VE } & & \\
\hline
\end{tabular}

Figura 5: Regionalização dos tempos de ativação ventricular.

Assim, após a individualização das regiões do VD, do septo e do VE pelo mapeamento eletrocardiográfico de superfície, calculamos o TAV médio do VD, o TAV médio do septo e o TAV médio do VE (média aritmética dos TAV's correspondentes de cada região) o que possibilitou a caracterização da sequência de ativação ventricular de maneira quantitativa.

Também determinamos a inter-relação entre estas regiões, pois calculamos o TEMPO DE ATIVAÇÃO VENTRICULAR INTER-REGIONAL, definido pela diferença (valor absoluto) entre o TAV do VD em relação ao TAV do VE, valor este também denominado diferença interventricular (TAV Inter-Regional ${ }_{\mathrm{VD}-\mathrm{VE}}$ ), a diferença entre o TAV do septo em relação ao TAV do VD (TAV Inter-Regional septo-vD) e a diferença entre o TAV do septo em relação ao TAV do VE (TAV Inter-Regional Septo-VE). 
Tanto a caracterização global quanto a regional possibilitou uma melhor compreensão dos fenômenos elétricos cardíacos, mais especificamente da interrelação das câmaras ventriculares.

Todos os tempos de ativação ventricular (Global, Regional e Inter-Regional) foram obtidos em dois momentos. O primeiro, durante a estimulação biventricular e o segundo durante o ritmo próprio (sinusal + BRE) após desligar o ressincronizador.

Para entendermos o efeito do ressincronizador na ativação elétrica ventricular, calculamos o que denominamos de DELTA TAV. Assim sendo, subtraímos o valor do TAV durante a estimulação biventricular do TAV durante ritmo sinusal + BRE (Global, Regional e Inter-Regional).

Portanto, a caracterização da ativação elétrica ventricular em pacientes portadores de TRC será feita através da obtenção dos TAV's:

1. durante ritmo sinusal $+\mathrm{BRE}$

2. durante estimulação biventricular

3. diferença entre estimulação biventricular - ritmo sinusal+BRE

Todas as oitenta e sete medidas dos tempos de ativação ventricular nas derivações do MES foram realizadas de maneira automática pelo equipamento Fukuda Denshi 7100. 
Em resumo, o estudo em questão irá utilizar os seguintes parâmetros fornecidos pelo mapeamento eletrocardiográfico de superfície:

TAV Global máximo (maior TAV obtido nas 87 derivações)

TAV Global médio (média aritmética dos TAV nas 87 derivações)

$\checkmark$ TAV Regional

- TAV do VD (média aritmética dos TAV na região do VD)

- TAV do Septo (média aritmética dos TAV na região do septo)

- TAV do VE (média aritmética dos TAV na região do VE)

$\checkmark$ TAV Inter-Regional

- TAV Inter-Regional VD-VE (diferença interventricular)

- TAV Inter-Regional Septo-VD

- TAV Inter-Regional Septo-VE

Delta TAV (Diferença entre o TAV durante estimulação biventricular e durante ritmo sinusal+BRE)

\section{Análise estatística:}

As variáveis contínuas são apresentadas como mediana. As medianas dos tempos de ativação ventricular global, regional e das diferenças inter-regionais obtidas durante ritmo sinusal + BRE e durante estimulação biventricular foram comparadas pelos testes não paramétricos de Mann-Whitney e Kruskal-Wallis. As variáveis categóricas são expressas em porcentagem, tendo sido utilizado o teste de Fisher. O nível de significância estabelecido foi $P \leq 0,05$. 
Capítulo IV

Resultados 


\section{Resultado:}

Os cinquenta e cinco pacientes estudados apresentavam idade média de $61 \pm$ 10 anos (I.C.95\%: 58 - 63 anos), sendo sessenta por cento do sexo masculino (33). A etiologia da cardiopatia mais frequente foi a idiopática, correspondendo a 51,0\% (28), seguida da isquêmica com $20,0 \%$ (11), da chagásica com $14,5 \%$ (8) e da hipertensiva $14,5 \%$ (8). O tempo médio de acompanhamento foi de $1.385 \pm 1.084$ dias (I.C.95\%: 1.092 - 1.679 dias) e a realização do mapeamento eletrocardiográfico de superfície ocorreu após aproximadamente 3 meses depois do implante do ressincronizador. As características clínicas e ecocardiográficas refletiram os critérios de seleção para o implante do ressincronizador, os quais determinavam que o paciente devesse apresentar baixa fração de ejeção do ventrículo esquerdo (FEVE) e elevada classe funcional da classificação NYHA além do aumento da duração do complexo QRS acima de 120 ms e da utilização das medicações para insuficiência cardíaca congestiva. Assim, a FEVE média foi de 0,29 \pm 0,10 (I.C.95\%: $0,26-0,31)$, com $84 \%(46)$ e $16 \%$ (9) dos pacientes em classe funcional III e IV, respectivamente e duração média do complexo QRS de $182 \pm 24$ ms (I.C.95\%: 176 189 ms). Os dados clínicos estão dispostos no Anexo A.

Como objetivo primário deste estudo, o comportamento da ativação elétrica ventricular destes pacientes foi analisado em dois momentos: durante o ritmo próprio (ritmo sinusal+BRE) e durante a estimulação biventricular. Além disso, calculamos o Delta TAV cujo resultado traduz a diferença entre a estimulação biventricular sobre o ritmo sinusal + BRE, e assim, mensuramos o efeito do 
ressincronizador sobre a ativação elétrica ventricular. Para tal, utilizamos para esta análise os parâmetros eletrocardiográficos já descritos na metodologia. Dentre os estudados temos o tempo de ativação ventricular global (TAV Global) máximo e médio, os tempos de ativação ventricular regional (TAV Regional) do septo e dos ventrículos direito e esquerdo e os tempos de ativação ventricular Inter-Regional (TAV Inter-Regional) VE-VD, Septo-VD e Septo-VE. Todos os valores dos TAV's encontram-se no Anexo B.

Na tabela 1 estão os valores encontrados durante o ritmo próprio do paciente, isto é, ritmo sinusal com bloqueio de ramo esquerdo. Os valores estão em milissegundos e dispostos como média \pm desvio-padrão, intervalo de confiança 95\%, mediana e valores mínimo-máximo.

Tabela 1: Ativação elétrica ventricular durante ritmo próprio (valores em milissegundos).

\begin{tabular}{|l|c|c|c|c|}
\hline Sinusal + BRE & Média \pm D.P. & I.C.95\% & Mediana & Mín-Máx \\
\hline TAV Global máximo & $135,9 \pm 5,9$ & $\begin{array}{c}134,4- \\
137,5\end{array}$ & 138 & $106-139$ \\
\hline TAV Global médio & $66,8 \pm 9,9$ & $64,2-69,4$ & 64,8 & $48,1-87,8$ \\
\hline TAV Regional VD & $51,9 \pm 15,4$ & $47,8-56,0$ & 54,5 & $21,7-86,9$ \\
\hline TAV Regional Septo & $56,9 \pm 17,2$ & $52,4-64,5$ & 56,4 & $29,1-115,3$ \\
\hline TAV Regional VE & $93,1 \pm 17,9$ & $88,3-97,8$ & 95,9 & $47,3-123,4$ \\
\hline TAV Inter-Regional VE-VD & $44,1 \pm 22,1$ & $38,3-49,9$ & 43,8 & $0,08-96,00$ \\
\hline TAV Inter-Regional S-VD & $10,8 \pm 10,7$ & $7,9-13,6$ & 6,9 & $0,02-59,48$ \\
\hline TAV Inter-Regional S-VE & $40,8 \pm 19,8$ & $35,5-46,0$ & 42,6 & $0,06-76,54$ \\
\hline
\end{tabular}

BRE: bloqueio de ramo esquerdo; TAV: tempo de ativação ventricular; VD: ventrículo direito; S: septo; VE: ventrículo esquerdo; D.P.: desvio-padrão; I.C.: intervalo de confiança; Mín: mínimo; Máx: máximo. 
Os mesmos dados da tabela 1 podem ser mais bem visualizados e comparados pelos gráficos 1,2 e 3.

Gráfico 1: TAV Global Máximo e Médio durante ritmo sinusal e BRE.

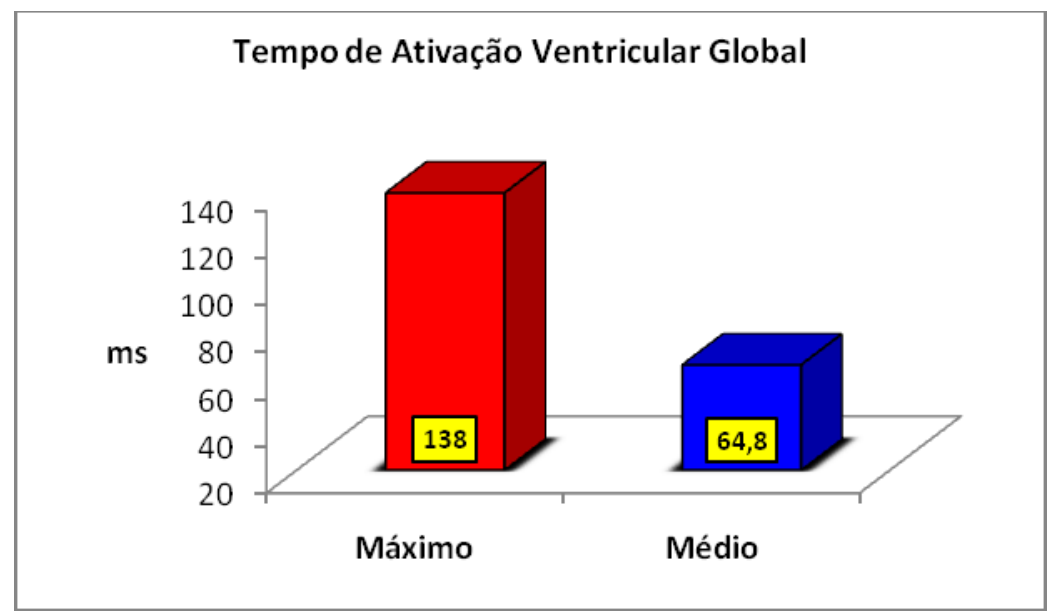

Gráfico 2: TAV Regional do VD, do Septo e do VE durante ritmo sinusal e BRE.

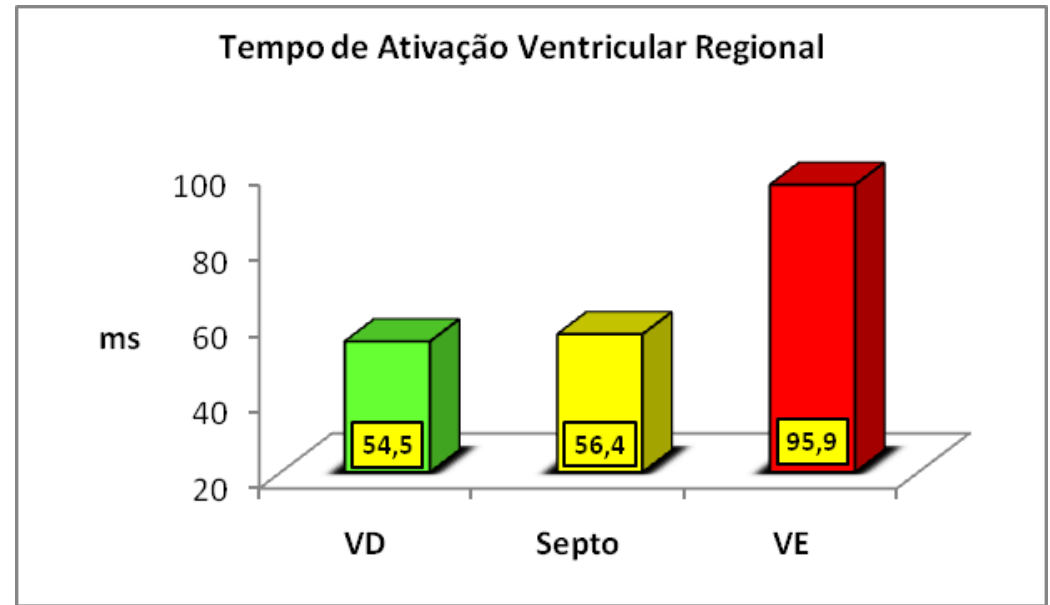

Gráfico 3: TAV Inter-Regional VE-VD, Septo-VD e Septo-VE durante ritmo sinusal e BRE.

Tempo de Ativação Ventricular Inter-Regional

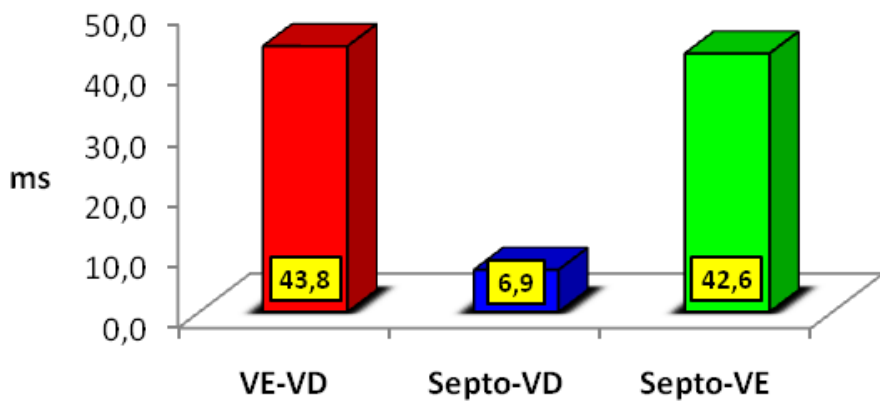


Os dados do gráfico 1 mostram, um TAV Global prolongado, tanto máximo quanto médio, na ativação elétrica ventricular durante o ritmo próprio, isto é, bloqueio de ramo esquerdo. No gráfico 2, ao interpretar os dados do TAV Regional, observamos uma significativa diferença entre a ocorrência das ativações das regiões do VD, do septo e do VE, caracterizando, numericamente, não apenas a sequência da ativação ventricular, mas também um grande atraso na ativação do ventrículo esquerdo, em relação à ativação do VD $(95,9 \mathrm{~ms} \times 54,5 \mathrm{~ms}, \mathrm{p}<0,001)$ e à do Septo (95,9 ms x 56,4 ms, $p<0,001)$. Finalmente, no gráfico 3 , podemos quantificar as diferenças acima descritas, através dos dados do TAV Inter-Regional. Demonstramos que além dos retardos serem significativos entre as regiões VE-VD e Septo-VE $(43,8$ ms e 42,6 ms, respectivamente, $p<0,001)$, a ativação entre a região Septo-VD é praticamente simultânea (6,9 ms).

Estes resultados fornecem, de maneira quantitativa, uma detalhada caracterização da ativação elétrica ventricular de pacientes portadores de bloqueio de ramo esquerdo.

Além das formas numérica e gráfica apresentadas, é possível visualizar e entender a ativação elétrica ventricular através do Mapa de Linhas Isócronas (figura 6), também fornecido pelo mapeamento elétrico de superfície. 


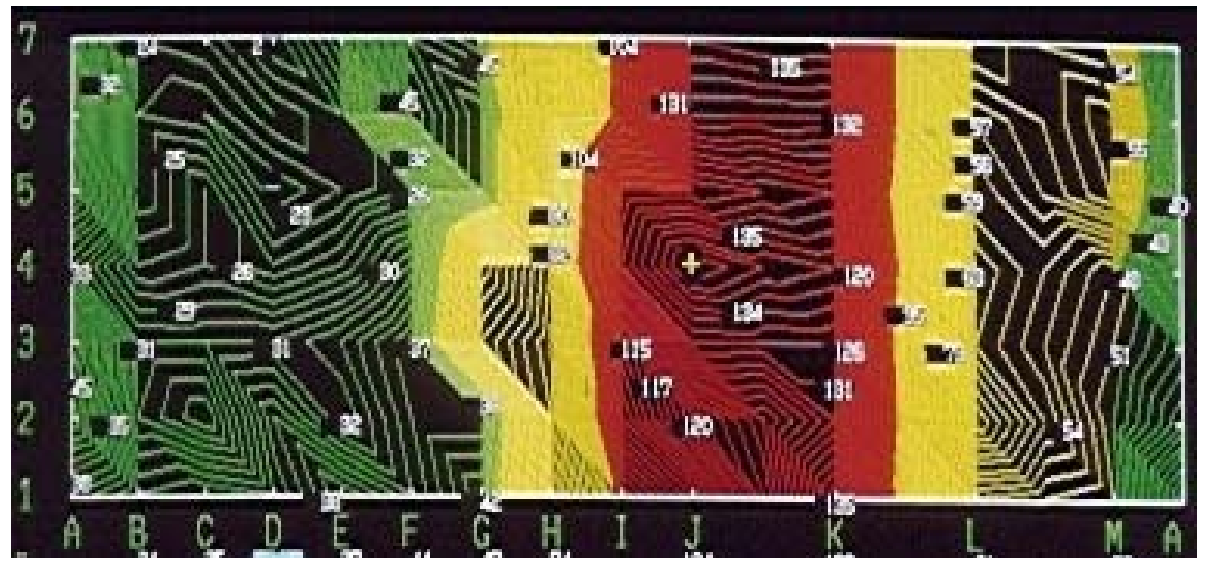

Figura 6: Mapa de linhas isócronas durante ritmo sinusal e BRE.

Como já descrito na metodologia, nesta maneira de apresentação dos dados, o mapa de linhas isócronas do MES também caracteriza a ativação elétrica ventricular de forma qualitativa através de cores (sequência de ativação) e da proximidade entre as linhas (velocidade de ativação). Dessa forma, foi possível notar na figura 6 (sempre tendo na lembrança a regionalização das áreas do VD, do septo e do VE mostradas na figura 5, página 18 ) que a ativação elétrica mais precoce (verde) iniciou-se pelo ventrículo direito, a seguir, chega à região central (septo) e posterior do ventrículo esquerdo, vistas pela cor amarela e finalmente terminou no ventrículo esquerdo (vermelho). Além disso, outra informação importante foi a velocidade de condução do estímulo elétrico por estas regiões. As linhas afastadas entre si denotam uma velocidade rápida, enquanto que as linhas mais próximas significam uma lentidão da condução do estímulo elétrico por estas regiões. Ficou evidente, neste caso da figura 6 que houve um significativo retardo da condução em parte da 
região do septo e do ventrículo esquerdo, compatível com o dado eletrocardiográfico da presença do bloqueio de ramo esquerdo.

Na tabela 2 estão colocados os tempos de ativação ventricular obtidos durante a estimulação biventricular, isto é, com o ressincronizador em funcionamento. Da mesma forma que antes, os valores estão em milissegundos e dispostos como médiaさdesvio-padrão, intervalo de confiança 95\%, mediana e valores mínimomáximo.

Tabela 2: Ativação elétrica ventricular durante estimulação biventricular (valores em milissegundos).

\begin{tabular}{|c|c|c|c|c|}
\hline Estimulação Biventricular & Média $\pm D . P$. & I.C.95\% & Mediana & Mín-Máx \\
\hline TAV Global máximo & $128,5 \pm 20,0$ & $123,2-133,8$ & 131 & $60-225$ \\
\hline TAV Global médio & $68,5 \pm 18,7$ & $63,6-73,4$ & 70,5 & $25,3-98,2$ \\
\hline TAV Regional VD & $71,4 \pm 26,6$ & $64,3-78,4$ & 78,9 & $20,0-126,5$ \\
\hline TAV Regional Septo & $60,4 \pm 19,3$ & $55,3-65,5$ & 59,6 & $22,6-101,6$ \\
\hline TAV Regional VE & $74,9 \pm 21,3$ & $69,2-80,5$ & 77,3 & $21,9-119,2$ \\
\hline TAV Inter-Regional VE-VD & $16,3 \pm 12,6$ & $13,0-19,7$ & 17,0 & $0,38-46,12$ \\
\hline TAV Inter-Regional S-VD & $19,3 \pm 15,7$ & $15,1-23,4$ & 16,0 & $0,69-83,21$ \\
\hline TAV Inter-Regional S-VE & $21,0 \pm 15,7$ & $16,9-25,2$ & 16,3 & $0,06-59,59$ \\
\hline
\end{tabular}

TAV: tempo de ativação ventricular; VD: ventrículo direito; S: septo; VE: ventrículo esquerdo;

D.P.: desvio-padrão; I.C.: intervalo de confiança; Mín: mínimo; Máx: máximo. 
A seguir, os mesmos dados da tabela 2 podem ser melhor visualizados pelos gráficos 4,5 e 6 .

Gráfico 4: TAV Global Máximo e Médio durante estimulação biventricular.

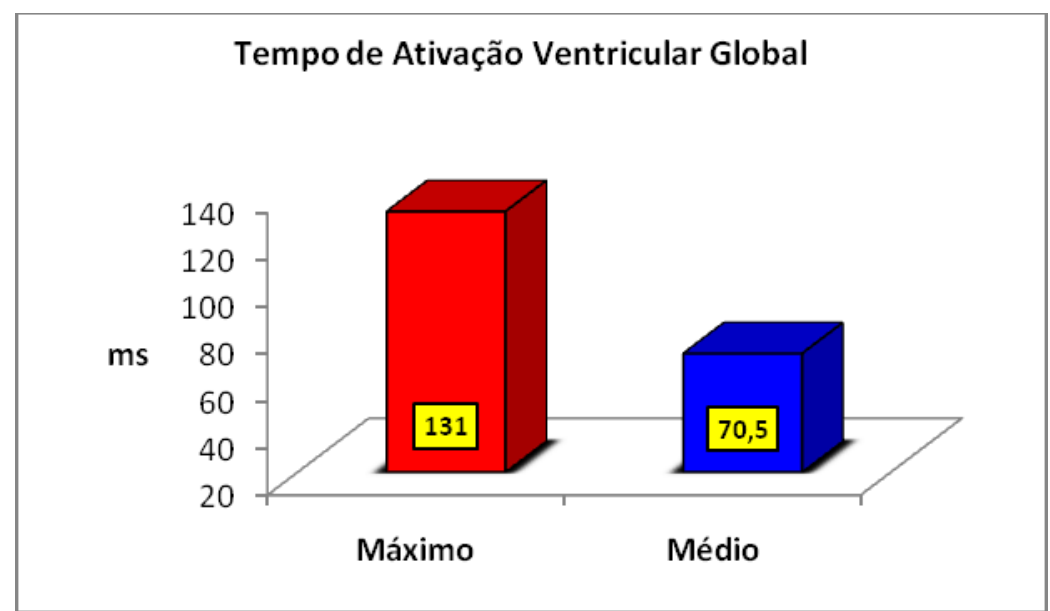

Gráfico 5: TAV Regional do VD, do Septo e do VE durante estimulação biventricular.

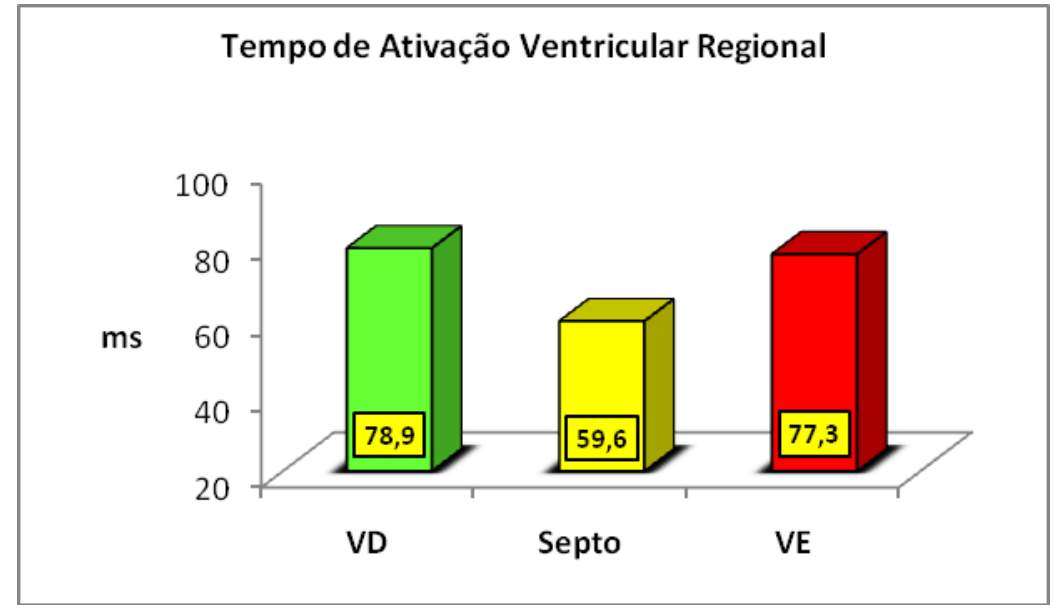

Gráfico 6: TAV Inter-Regional VE-VD, Septo-VD e Septo-VE durante estimulação biventricular.

Tempo de Ativação Ventricular Inter-Regional

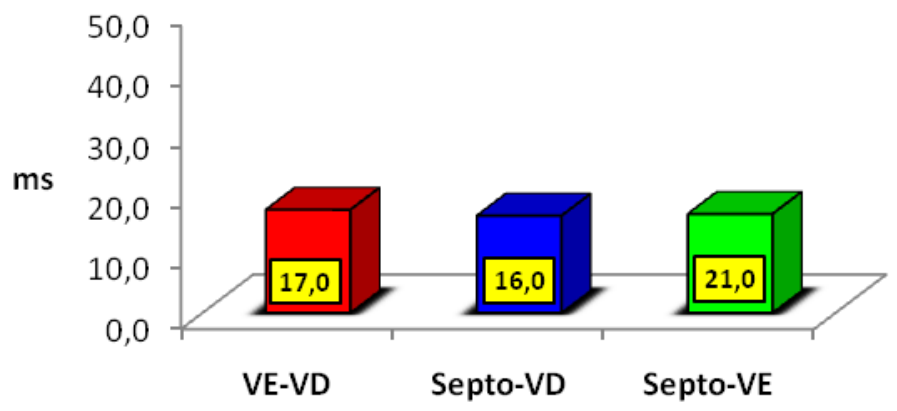


Os dados do gráfico 4 mostram que durante a estimulação biventricular, ocorreu um comportamento antagônico em relação ao TAV Global. Constatamos uma redução do TAV Global máximo (131 ms) e um discreto aumento do TAV Global médio (70,5 ms). Estes resultados podem ser melhor compreendidos através do gráfico 5, no qual ficou evidente o efeito do ressincronizador sobre as mudanças no TAV Regional (78,9 ms x 59,6 ms x 77,3 ms, VD, septo e VE, respectivamente; $p<0,001)$, e observou-se uma equiparação entre os tempos de ativação das regiões do ventrículo direito e do ventrículo esquerdo $(78,9 \mathrm{~ms} \times 77,3 \mathrm{~ms}$, VD e VE, respectivamente; $p=n s)$, ambos mais prolongados do que a região do septo (78,9 ms x 59,6 ms, VD e septo, respectivamente; $p<0,01$ e 77,3 ms x 59,6 ms, VE e septo; respectivamente, $p<0,01)$. Finalmente, no gráfico 6 , foi inequívoca a influência do ressincronizador no TAV Inter-Regional, no qual percebemos uma clara simultaneidade temporal entre VE-VD, Septo-VD e Septo-VE $(17,0 \mathrm{~ms} \times 16,0 \mathrm{~ms} \times$ 21,0 ms, respectivamente; $p=n s)$.

Como na situação anterior, isto é, durante ritmo sinusal + BRE, reproduzimos os achados da ativação elétrica ventricular durante a estimulação biventricular através dos dados qualitativos fornecidos pelo Mapa de Linhas Isócronas (figura 7). 


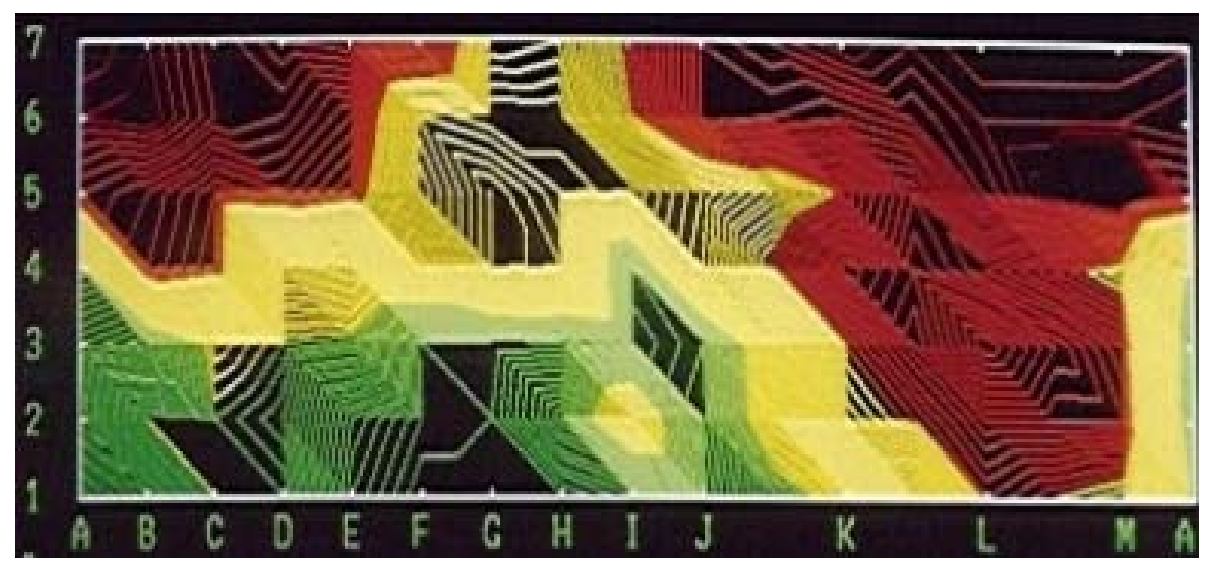

Figura 7: Mapa de linhas isócronas durante estimulação biventricular.

Com o ressincronizador em funcionamento, foi possível perceber que a ativação elétrica ventricular ocorre quase que simultaneamente nas três regiões estudadas, isto é, ventrículo direito, septo e ventrículo esquerdo, de forma semelhante ao que aconteceu durante o ritmo sinusal normal (figura 3). Utilizando a informação de cores, notou-se que a ativação elétrica ventricular, na figura 7 , iniciou-se nas áreas verdes (ventrículo direito, septo e pequena parte do ventrículo esquerdo), a seguir, chegou às regiões médias do VD, do septo e do VE e terminou na região basal do ventrículo direito e o restante do ventrículo esquerdo. Ao observarmos a distância entre as linhas, isto é, o dado que caracteriza a velocidade em que a ativação ocorre no músculo cardíaco, percebemos que houve uma distribuição semelhante entre as regiões de velocidades mais lentas (linhas próximas) e mais rápidas (linhas afastadas) do estímulo elétrico ventricular. Muito importante ressaltar a concomitância em que todas as regiões foram ativadas durante a estimulação biventricular, ao contrário do exemplo da figura 6 . 
Portanto, com os resultados obtidos durante ritmo sinusal + bloqueio de ramo esquerdo e durante a estimulação biventricular, foi possível caracterizar quantitativamente e qualitativamente o comportamento elétrico cardíaco dos indivíduos submetidos ao implante do ressincronizador.

A tabela 3 apresenta a comparação dos parâmetros eletrocardiográficos estudados em ambas as situações, a variação percentual dos mesmos (estimulação biventricular - ritmo sinusal + BRE) e os dados estão expostos como mediana e seus respectivos valores de $p$.

Tabela 3: Comportamento da ativação elétrica ventricular (valores em milissegundos).

\begin{tabular}{|l|c|c|c|c|}
\hline & Sinusal + BRE & $\begin{array}{c}\text { Estimulação } \\
\text { Biventricular }\end{array}$ & Variação & p \\
\hline TAV Global máximo & 138 & 131 & $\downarrow 5,1 \%$ & 0,007 \\
\hline TAV Global médio & 64,8 & 70,5 & $\uparrow 8,8 \%$ & $\mathrm{~ns}$ \\
\hline TAV Regional VD & 54,5 & 78,9 & $\uparrow 44,8 \%$ & 0,001 \\
\hline TAV Regional Septo & 56,4 & 59,6 & $\uparrow 5,7 \%$ & $\mathrm{~ns}$ \\
\hline TAV Regional VE & 95,9 & 77,3 & $\downarrow 19,4 \%$ & 0,001 \\
\hline TAV Inter-Regional VE-VD & 43,8 & 17,0 & $\downarrow 61,2 \%$ & 0,001 \\
\hline TAV Inter-Regional S-VD & 6,9 & 16,0 & $\uparrow 132 \%$ & 0,002 \\
\hline TAV Inter-Regional S-VE & 42,6 & 16,3 & $\downarrow 61,7 \%$ & 0,001 \\
\hline
\end{tabular}

BRE: bloqueio de ramo esquerdo; TAV: tempo de ativação ventricular; VD: ventrículo direito; S: septo; VE: ventrículo esquerdo; ns: não significativo.

Os gráficos 7 a 10, colocados a seguir, reproduzem os dados da tabela 3 e facilitam a visualização, a comparação e a compreensão destes achados.

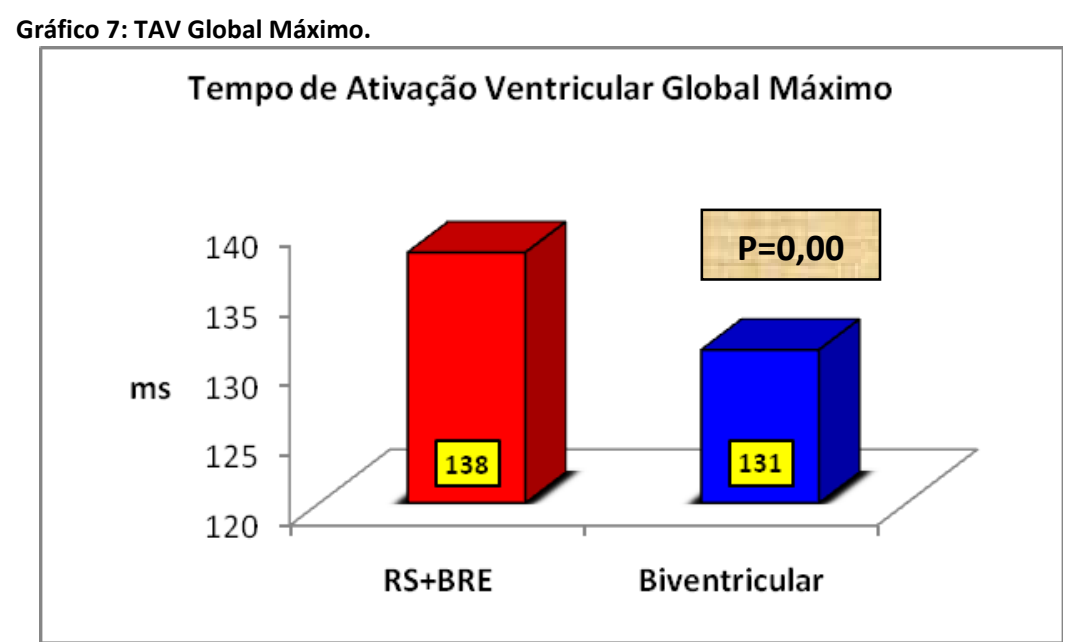


Gráfico 8: TAV Global Médio.

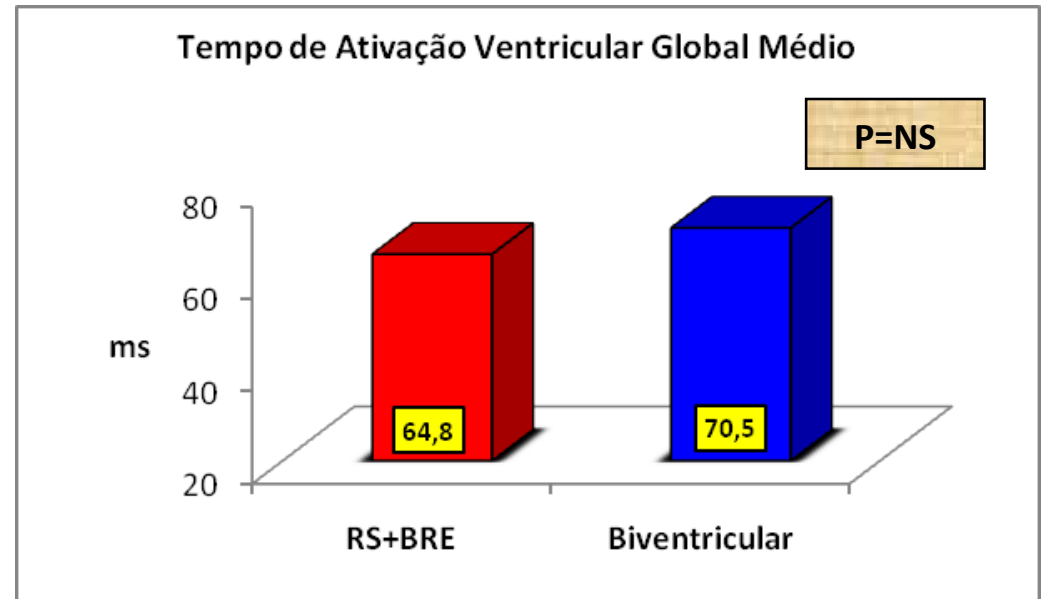

Gráfico 9: TAV Regional do VD, do Septo e do VE.

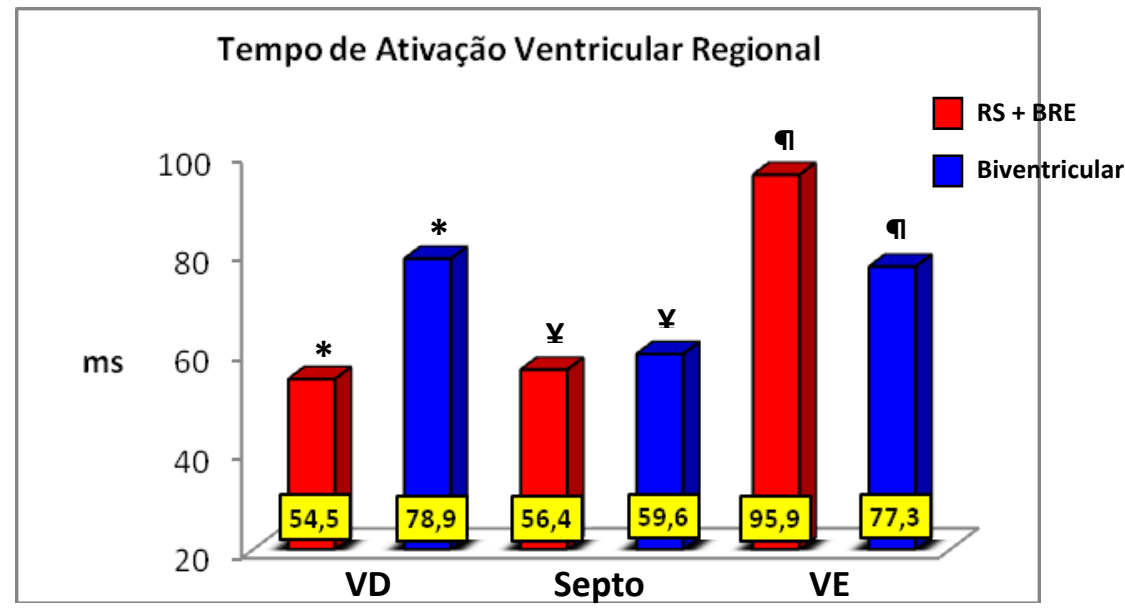

$*: p=0,001 ; ¥: p=n s ; \uparrow: p=0,001$.

Gráfico 10: TAV Inter-Regional VE-VD, Septo-VD e Septo-VE.

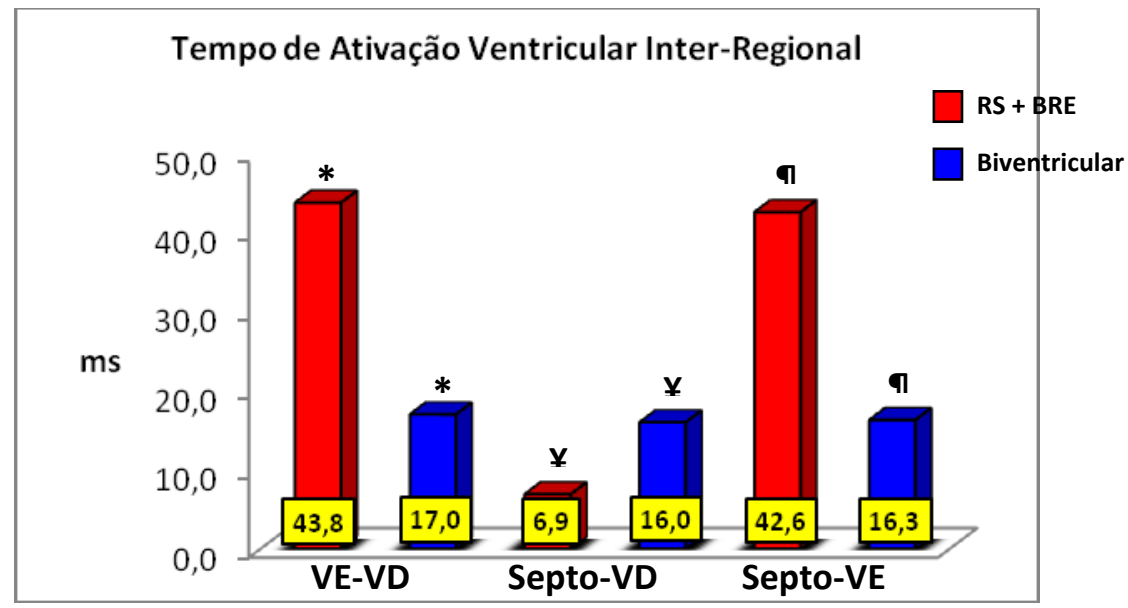

$*: p=0,001 ; ¥: p=0,002 ; \uparrow: p=0,001$ 
Nos gráficos 7 e 8, evidenciamos o comportamento antagônico do TAV Global, com significativa redução do TAV Global máximo (138 ms x 131 ms, p=0,007) e um aumento não significativo do TAV Global médio $(64,8 \mathrm{~ms} \times 70,5 \mathrm{~ms})$ durante a estimulação biventricular.

Estes achados podem ser entendidos pelas modificações do TAV Regional durante a estimulação biventricular, colocadas no gráfico 9. Ficou muito claro que o ressincronizador em funcionamento reduziu significativos 19,4\% do TAV Regional do ventrículo esquerdo quando comparado à situação de ritmo sinusal + BRE $(95,9$ ms $x$ 77,3 ms, $p=0,001)$. Como o TAV Global máximo sofre influência direta da câmara mais atrasada (VE), a sua significativa redução durante a estimulação biventricular refletiu, diretamente, a também significativa redução do TAV Regional do VE, uma vez que os valores máximos desta câmara foram reduzidos. Concomitantemente, notou-se que o TAV Regional do ventrículo direito sofreu um significativo aumento de $44,8 \%$ durante a estimulação biventricular $(54,5$ ms x 78,9 ms, $p=0,001)$. Em relação ao TAV Regional do septo não encontramos modificações significativas $(56,4 \mathrm{~ms} \times 59,6 \mathrm{~ms}, \mathrm{p}=\mathrm{ns})$. Essas mudanças explicam o comportamento do TAV Global médio (aumento durante a estimulação biventricular), pois para seu cálculo, foi feita a média aritmética dos TAV's nas 87 derivações. Apesar da redução do TAV Regional do VE em 19,4\%, houve um aumento do TAV Regional do VD de de $44,8 \%$ e do TAV Regional do Septo de 5,7\%. 
O gráfico 10 permite a visualização do fenômeno elétrico entre as regiões nos dois momentos estudados. Com o ressincronizador em funcionamento, houve uma significativa redução de $61,2 \%$ do TAV Inter-Regional VE-VD ou TAV Interventricular $(43,8 \mathrm{~ms} \times 17,0 \mathrm{~ms}, \mathrm{p}=0,001)$. O mesmo se observou com o TAV Inter-Regional septove que apresentou uma redução de $61,7 \%(42,6 \mathrm{~ms} \times 16,3 \mathrm{~ms}, \mathrm{p}=0,001)$. Como consequência do aumento do TAV Regional do VD, verificamos também um significativo aumento de $132 \%$ do TAV Inter-Regional septo-vD $(6,9 \mathrm{~ms} \times 16,0 \mathrm{~ms}$, $p=0,002)$.

Com estes resultados, ficou evidente que, do ponto de vista elétrico, o ressincronizador tentou restabelecer o pareamento ventricular nestes pacientes, perdido durante o bloqueio de ramo esquerdo. Esse pareamento ocorreu tanto pela antecipação da ativação do VE quanto pelo retardo da ativação do VD.

Para avaliarmos o efeito do ressincronizador sobre a ativação elétrica ventricular dos pacientes estudados, calculamos o Delta TAV, isto é, a diferença, em milissegundos, dos TAV's (Global, Regional e Inter-Regional) durante a estimulação biventricular em relação ao ritmo sinusal + BRE. Esses resultados estão colocados na tabela 4.

Tabela 4: Delta TAV - Diferença entre os TAV's da estimulação biventricular e o ritmo sinusal + BRE.
\begin{tabular}{|l|c|}
\hline & Delta TAV (ms) \\
\hline TAV Global máximo & $(7,0)$ \\
\hline TAV Global médio & 6,4 \\
\hline TAV Regional VD & 28,9 \\
\hline TAV Regional Septo & 5,1 \\
\hline TAV Regional VE & $(17,3)$ \\
\hline TAV Inter-Regional VE-VD & $(40,3)$ \\
\hline TAV Inter-Regional S-VD & 5,1 \\
\hline TAV Inter-Regional S-VE & $(21,5)$ \\
\hline & BRE: bloqueio de ramo esquerdo; TAV: tempo de ativação ventricular; \\
& VD: ventrículo direito; S: septo; VE: ventrículo esquerdo.
\end{tabular}


Os mesmos dados da tabela 4 estão expostos nos gráficos 11, 12 e 13 para melhor visualização e compreensão.

Gráfico 11: Delta TAV Global Médio.

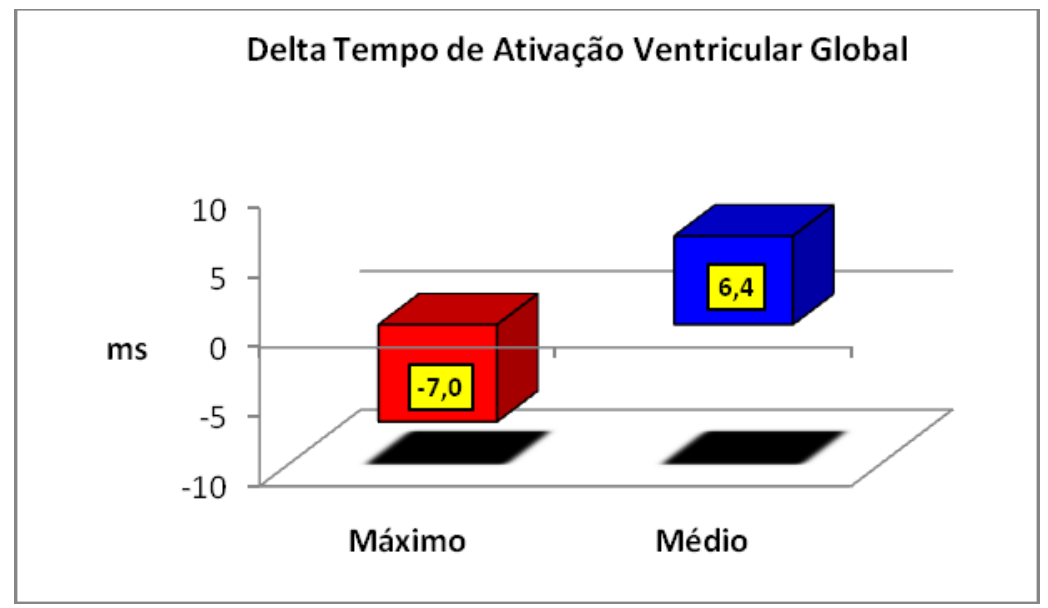

Gráfico 12: Delta TAV Regional do VD, do Septo e do VE.

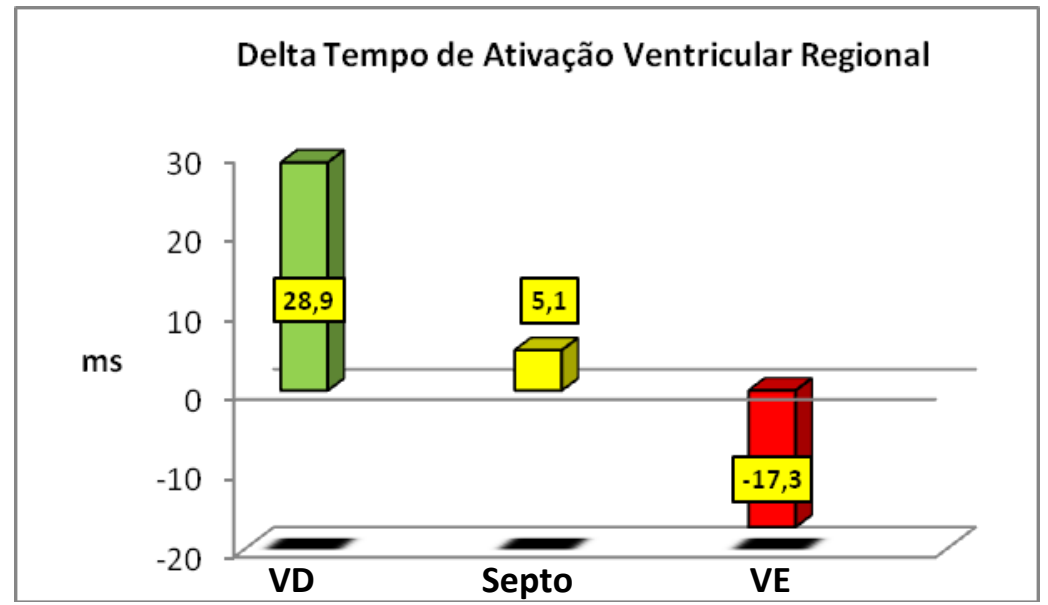

Gráfico 13: Delta TAV Inter-Regional VE-VD, Septo-VD e Septo-VE.

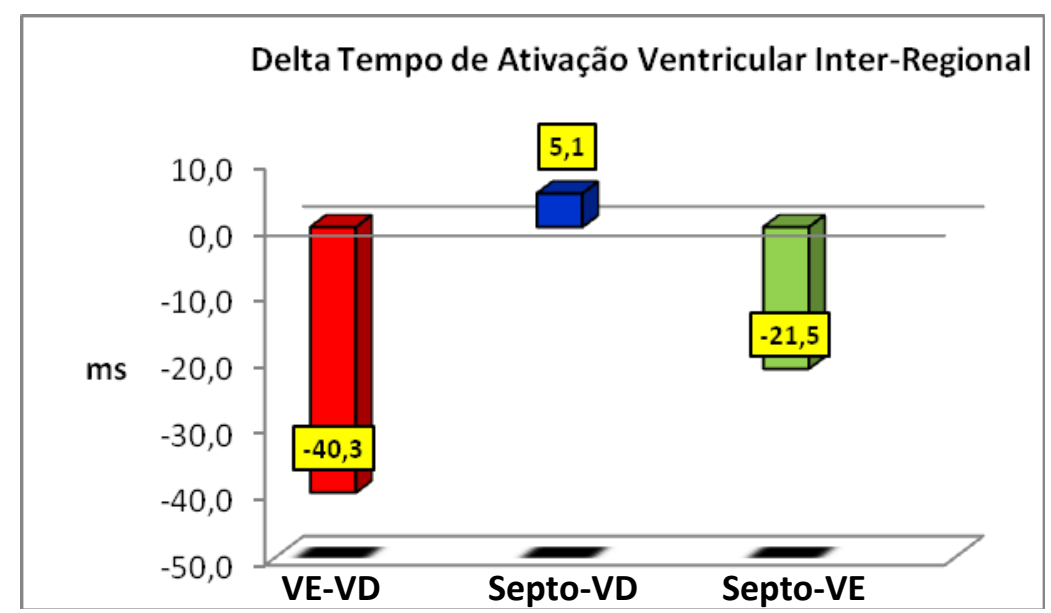


Para melhor entendermos os efeitos antagônicos da estimulação biventricular sobre a ativação elétrica ventricular, no que se refere ao TAV Global máximo e médio devemos observar os dados do gráfico 11. Como já descrito, apesar da significativa redução do TAV Global máximo, ocorreu um aumento do TAV Global médio (gráficos 7 e 8). A mensuração do efeito da estimulação biventricular foi realizada com o cálculo do Delta TAV (diferença entre o TAV durante a estimulação biventricular em relação ao TAV durante ritmo sinusal + BRE), e observamos que o Delta TAV Global máximo foi de $-7,0$ ms e que o Delta TAV Global médio foi de 6,4ms, isto é, houve uma redução do TAV Global máximo e um aumento do TAV Global médio durante a estimulação biventricular. Esses achados são totalmente explicados pelos fenômenos elétricos que ocorrem regionalmente e estão bem exemplificados no gráfico 12. Observamos que o efeito da estimulação biventricular aumentou os valores do Delta TAV Regional do VD $(28,9 \mathrm{~ms})$ e do Delta TAV Regional do Septo $(5,1 \mathrm{~ms})$. Esse fenômeno superou a diminuição do Delta TAV Regional VE (-17,3 ms), fazendo com que a média do TAV Global aumentasse. Por outro lado, com a redução significativa do TAV Regional do VE, os valores individuais correspondentes à região do ventrículo esquerdo também caíram. Dessa forma, é possível entendermos a significativa queda do valor do TAV Global máximo. Finalmente, ao analisarmos o efeito do ressincronizador do ponto de vista Inter-Regional, percebemos como o funcionamento do aparelho modifica a ativação elétrica ventricular (gráfico 13). Ficou evidente, pelo Delta TAV InterRegional VE-VD (-40,3 ms) que a estimulação biventricular encurtou significativamente a diferença de tempos entre o ventrículo esquerdo em relação 
ao ventrículo direito. O mesmo fenômeno ocorreu em menor intensidade entre o septo e o ventrículo esquerdo que apresentaram um Delta TAV Inter-Regional SeptoVE de $-21,5$ ms. Não evidenciamos mudança significativa sobre os tempos entre o septo e o ventrículo direito, que apresentou Delta TAV Inter-Regional Septo-VD de 5,1 ms. 
Capítulo V 
Atualmente, os resultados da terapia de ressincronização cardíaca são incontestáveis, entretanto, a presença dos não respondedores também é uma constante. Como citado anteriormente, diversos estudos, com as mais variadas técnicas, foram feitos para o melhor entendimento do fenômeno eletromecânico cardíaco de pacientes com indicação de TRC, visando à redução do número de não respondedores.

Nosso trabalho faz parte de uma linha de pesquisa iniciada em meados da década de 90, quando o mapeamento eletrocardiográfico de superfície (MES) foi utilizado no estudo de pacientes portadores de bloqueio de ramo esquerdo (Pastore et al. em 1996). Após dez anos, foram publicados os primeiros estudos do Grupo que envolveram a TRC e o mapa de linhas isócronas, fornecido pelo MES (Pastore et al. em 2006 e 2007), nos quais, foram definidas as primeiras características da ativação elétrica ventricular desta população, bem como a possibilidade de regionalização das informações obtidas pelas oitenta e sete derivações do MES.

No estudo atual, o número de pacientes envolvidos foi quase duas vezes maior, e conseguimos reproduzir e ratificar os resultados do trabalho anterior. Dessa maneira, as 87 derivações do mapeamento eletrocardiográfico de superfície foram utilizadas para caracterizar, do ponto de vista elétrico, a ativação ventricular de pacientes submetidos à terapia de ressincronização cardíaca, de forma qualitativa (sequência de cores e proximidade das linhas isócronas) e quantitativa (matriz contendo os tempos de ativação ventricular). Na primeira, as imagens do MES são muito claras, a ponto de podermos rapidamente distinguir um MES de um paciente normal, de um com bloqueio de ramo esquerdo e de um submetido à TRC (Anexo 
C). Em relação às características quantitativas, utilizamos os valores médio e máximo do TAV Global (87 derivações), o valor médio do TAV Regional do VD, do Septo e do VE. Além disso, a análise mais detalhada das regiões do MES, relacionadas ao ventrículo direito, ao septo e ao ventrículo esquerdo, possibilitou a elaboração de uma nova característica da ativação elétrica ventricular: o Tempo de Ativação Ventricular Inter-Regional (TAV Inter-Regional), que foi acrescentada à análise quantitativa como uma nova medida: o TAV Inter-Regional VE-VD, SeptoVD e Septo-VE. Todas estas medidas foram feitas nos cinquenta e cinco pacientes, tanto com o ressincronizador ligado (estimulação biventricular) como desligado (ritmo sinusal + BRE).

\section{Avaliação do Tempo de Ativação Ventricular durante o BRE}

Inicialmente, durante ritmo sinusal + BRE, ficou bastante evidente o grande atraso que há no TAV Global máximo e médio, quando comparamos com os dados de indivíduos normais de Pastore et al. (2006). Também reproduzimos o acontecimento praticamente simultâneo da ativação das regiões do ventrículo direito e do septo, e do atraso significativo do TAV Regional do VE, em relação a ambas. O TAV Regional do VE apresentou-se com valor $80 \%$ e $64 \%$ maior quando comparado ao TAV Regional do VD e ao TAV Regional do Septo, respectivamente, culminando num prolongado TAV Inter-Regional VE-VD, com um TAV Inter-Regional SeptoVE igualmente longo. Já o TAV Inter-Regional Septo-VD mostrou-se curto, justificado pela ativação concomitante entre VD e septo. Portanto, são características da condição eletrocardiográfica de bloqueio de ramo esquerdo, vistas pelo MES, os 
achados de um TAV Global acima de $120 \mathrm{~ms}$, um TAV médio acima de $60 \mathrm{~ms}$, o retardo regional do TAV do VE em relação ao do VD e ao do Septo, bem como o prolongado TAV Inter-Regional VE-VD e Septo-VE.

O reconhecimento dessa mesma condição eletrocardiográfica de bloqueio de ramo esquerdo, analisada através dos dados qualitativos fornecidos pelo MES, é intuitiva e facilita a interpretação dos números acima apresentados. Lembrando a disposição dos oitenta e sete eletrodos (figura 2, página 15) e a correlação destes com as regiões do ventrículo direito, do septo e do ventrículo esquerdo (figura 5, página 19), é possível definir como inconfundível o MES de um indivíduo com BRE. A ativação elétrica ventricular, vista pelas linhas isócronas verdes, iniciou-se na região do VD, logo a seguir as linhas tornaram-se amarelas e a ativação atingiu a região do Septo e terminou na região do VE com as linhas isócronas em vermelho. Em relação à velocidade da ativação elétrica ventricular, percebemos claramente linhas mais afastadas na região do VD e parte do Septo (velocidade rápida), que ficaram muito próximas (velocidade lenta) ainda no Septo e em grande parte da região do VE, como exemplificado na figura 6 (página 27). Assim, com os dados quantitativos e qualitativos obtidos, conseguimos caracterizar em detalhes a ativação elétrica ventricular de pacientes com bloqueio de ramo esquerdo.

Os estudos que analisaram a ativação elétrica de indivíduos com BRE utilizaram o mapeamento eletroanatômico, método invasivo, para esta caracterização (Rodriguez et al. em 2003, Peichl et al. em 2004, Auricchio et al. em 2004b, Fantoni et al. em 2005). Além da metodologia ser diferente da apresentada neste estudo, não há, em qualquer um deles, uma discriminação e quantificação clara dos tempos em que essa ativação ocorre no ventrículo direito, no septo e no ventrículo esquerdo e, 
tão pouco, da relação inter-regiões. Todos os quatro têm em comum o achado de um grande retardo na ativação do $\mathrm{VE}$, em relação ao $\mathrm{VD}$, que varia de $89 \mathrm{~ms}$ a $110 \mathrm{~ms}$, exatamente como descrevemos e quantificamos (TAV Regional do VE de $96 \mathrm{~ms}$ ). Apenas Fantoni et al. (2005) apresenta um gráfico que mostra os tempos de ativação do VD de todos os pacientes estudados, onde é possível inferir uma média ao redor de $75 \mathrm{~ms}$. Em nosso estudo, também encontramos este valor médio prolongado (TAV Regional do VD de $55 \mathrm{~ms}$ ), porém 33\% menor.

\section{Avaliação do Tempo de Ativação Ventricular durante a TRC}

$\mathrm{Na}$ tentativa de esclarecer, e até mudar paradigmas sobre o entendimento do fenômeno elétrico, proporcionado pela terapia de ressincronização cardíaca, determinamos as medidas dos Tempos de Ativação Ventricular Global, Regional e Inter-Regional, encontradas durante a estimulação biventricular.

Com o ressincronizador ligado, observamos uma significativa redução do TAV Global máximo (138 ms x $131 \mathrm{~ms}, \mathrm{p}=0,007)$, porém um discreto aumento do TAV Global médio (64,8 ms x 70,5 ms, p=ns). Este comportamento do TAV Global, aparentemente sem sentido, é totalmente explicado pelas mudanças ocorridas no TAV Regional durante a estimulação biventricular. A TRC promove uma antecipação do TAV Regional do ventrículo esquerdo, com redução de quase $20 \%$ deste $(95,9 \mathrm{~ms} \times 75,3 \mathrm{~ms}, \mathrm{p}=0,001)$. Devemos lembrar que, na situação de BRE, o TAV Global máximo reflete os enormes tempos de ativação do ventrículo esquerdo, portanto, com a redução do TAV Regional do VE durante a TRC, haverá, concomitantemente, uma diminuição do TAV Global máximo. Por outro lado, ocorre 
um retardo de quase 45\% no TAV Regional do ventrículo direito (54,5 ms x 78,9 ms, $\mathrm{p}=0,001$ ), durante a estimulação biventricular. A elevação da média do TAV Regional do VD, somada à elevação não significativa em 5,7\% da média do TAV Regional do Septo (56,4 ms x 59,6 ms), é superior à redução do TAV Regional do VE, e portanto, ocorre um aumento do TAV Global médio durante a estimulação biventricular.

Para entendermos estes fenômenos elétricos, devemos lembrar do propósito do ressincronizador que é restaurar a mecânica ventricular, isto é, restabelecer a sincronia dos ventrículos. Esta sincronia (ou dissincronia) pode ser melhor avaliada pela relação temporal entre as regiões ventriculares. Para tal, definimos o TAV InterRegional (diferença entre as médias dos TAV's Regionais do VD, do Septo e do VE). Ao contrário do encontrado na situação de ritmo sinusal e BRE, durante a estimulação biventricular observamos uma significativa redução de $61 \%$ do TAV Interventricular, também chamado de TAV Inter-Regional VE-VD (43,8 ms x 17,0 $\mathrm{ms}, \mathrm{p}=0,001)$. Comportamento muito semelhante ocorreu com o TAV Inter-Regional Septo-VE que mostrou uma redução significativa de quase $62 \%(42,6 \mathrm{~ms} \times 16,3 \mathrm{~ms}$, $p=0,001$ ) durante a TRC. A redução destes TAV's Inter-Regionais evidenciam uma aproximação do momento em que ocorrem as ativações do VE com o VD e do VE com o septo, respectivamente, determinadas pela TRC. Finalmente, o aumento do TAV Regional do VD (já mencionado) determinou um aumento de $132 \%$ do TAV Inter-Regional Septo-VD (6,9 ms x 16,0 ms, p=0,002). Com estes resultados, evidenciamos, ao menos do ponto de vista elétrico, que os ventrículos direito e esquerdo tornaram-se sincrônicos durante a estimulação biventricular. 
Mais uma vez, a análise quantitativa fornecida pelo MES corrobora com os resultados acima descritos. Durante a TRC, observa-se que a ativação elétrica ventricular iniciou-se praticamente de forma simultânea pela porção apical das regiões do VD, do septo e do VE (linhas verdes), atingiu a porção média das mesmas três regiões (linhas amarelas) e terminou na porção basal do VD, do septo e do VE concomitantemente (linhas vermelhas), como exemplificado na figura 7 (página 31). Já a velocidade da ativação elétrica ventricular durante a estimulação biventricular mostrou-se mais lenta em todas as regiões estudadas (VD, septo e VE), pois as linhas isócronas apresentavam-se muito próximas entre si. Este achado pode ser interpretado pela posição dos eletrodos ventriculares, situados distantes do sistema elétrico de condução, fazendo com que a propagação do impulso elétrico ocorra célula a célula, e portanto, mais lentamente.

Como dito anteriormente, as metodologias empregadas nos estudos da ativação ventricular são distintas, porém os resultados apresentados por Varma et al. em 2007 mostraram que a TRC determinou um tempo de ativação do VD e do VE de 63,0 ms e 83,5 ms, respectivamente, sendo estes valores muito parecidos com os nossos dados (78,9 ms e 77,3 ms, VD e VE, respectivamente). O autor também descreve uma clara mudança da ativação do VD (aumento de $37 \mathrm{~ms}$ para $63 \mathrm{~ms}$ ) e do VE (redução de 113 ms para 83,5 ms) após a ressincronização, comportamento idêntico ao observado em nosso estudo (VD: $54,5 \mathrm{~ms} \rightarrow 78,9 \mathrm{~ms}$ e VE: $95,9 \mathrm{~ms} \rightarrow 77,3 \mathrm{~ms}$ ). Em ambos os trabalhos, é possível perceber uma aproximação dos tempos de ativação ventricular do VD em relação ao VE. Já Pretola et al. (2010) encontraram um tempo de ativação total de $68,5 \mathrm{~ms}$, bastante semelhante ao nosso TAV Global médio de 70,5 ms, durante a estimulação biventricular. Em 2010, Sassone et al. 
publicaram um trabalho com resultados interessantes e muito parecidos com os nossos, em especial sobre o que denominamos de TAV Interventricular (ou TAV Inter-Regional VE-VD), mesmo com uma metodologia totalmente diferente. Os autores denominaram de retardo elétrico intereletrodo VD-VE a diferença de tempo entre os eletrogramas intracavitários obtidos a partir do eletrodo do ventrículo direito em relação ao eletrodo do ventrículo esquerdo, ao final do implante do ressincronizador. Após seis meses de seguimento, constataram que essa medida foi significativamente diferente nos grupos de respondedores e não respondedores $(22,1$ ms x 43,6 ms, respectivamente). Em nosso estudo, o TAV Inter-Regional VE-VD foi de 17,0 ms, durante a estimulação biventricular. Esta medida, como será exposto adiante, pode ter um significado extremamente valioso para guiar a colocação dos eletrodos ventriculares, para ajustar a programação de tempo de estimulação entre eles, além de poder identificar aqueles indivíduos que mais se beneficiarão do implante do ressincronizador.

\section{Delta TAV: o efeito da TRC na ativação elétrica ventricular}

Para sedimentar nossos achados sobre os tempos de ativação ventricular, calculamos o Delta TAV. Essa medida foi obtida pela diferença entre os TAV's (Global, Regional e Inter-Regional) durante a estimulação biventricular e durante o BRE. Esta é mais uma maneira de caracterizar e entender o efeito da terapia de ressincronização cardíaca sobre a ativação elétrica ventricular. Assim, com o Delta TAV, demonstramos que a TRC reduziu o TAV Global máximo em 7,0 ms, aumentou o TAV Global médio em 6,4 ms, aumentou o TAV Regional do VD e do 
Septo em 28,9 ms e 5,1 ms, respectivamente, reduziu o TAV Regional do VE em 17,3 ms, reduziu o TAV Inter-Regional VE-VD e Septo-VE em 40,3 ms e 21,5 ms, respectivamente e aumentou o TAV Inter-Regional do septo-VD em 5,1 ms.

Estes achados são de extrema importância, pois, pela primeira vez na literatura, demonstram, detalhadamente, as mudanças que ocorrem na ativação ventricular global e regional durante o funcionamento do ressincronizador, tanto com dados qualitativos quanto por dados quantitativos. Estas informações podem servir como base para futuros estudos, envolvendo a terapia de ressincronização cardíaca e desfechos clínicos, como serão sugeridos, a seguir.

\section{Perspectivas clínicas}

Desde o início do trabalho, nossa intenção foi caracterizar os fenômenos elétricos ventriculares, utilizando o mapeamento eletrocardiográfico de superfície, em indivíduos portadores de ressincronizador cardíaco. Está bastante claro, desde a metodologia, que nosso trabalho não foi desenhado, e portanto, não possui condições científicas e estatísticas para responder questões relacionadas a desfechos clínicos. No entanto, no sentido da investigação clínica, e, portanto sempre voltados à possibilidade de aplicação prática dos diversos exames subsidiários em nossos pacientes, correlacionamos os nossos achados elétricos com alguns dados clínicos obtidos ao longo do trabalho, com o objetivo de identificar possibilidades futuras de investigação nesta linha de pesquisa. Dentre eles, utilizamos a informação da evolução da classe funcional após o implante do ressincronizador e a mortalidade total do grupo estudado. Naturalmente, com toda a limitação científica para tal 
análise, os resultados que serão apresentados a seguir, servem para suscitar, não apenas a curiosidade, mas também reais possibilidades de aplicação do MES nesta população, podendo, no futuro, vir a fazer parte dos exames subsidiários, hoje consagrados na literatura.

Como vimos, a terapia de ressincronização cardíaca tende, do ponto de vista elétrico, a equiparar os tempos de ativação ventricular das regiões do ventrículo esquerdo em relação ao do direito. A medida utilizada para aferir este efeito foi o TAV Interventricular, também denominado de TAV Inter-Regional VE-VD.

O primeiro parâmetro clínico analisado foi o comportamento da classe funcional (NYHA) antes e após 899 dias (mediana) do implante do ressincronizador, e constatamos que $80 \%$ dos pacientes apresentaram melhora clínica, com redução da classe funcional. Os $20 \%$ restantes foram considerados não respondedores.

Constatamos um TAV Interventricular significativamente menor, durante a estimulação biventricular, nos indivíduos que apresentaram melhora da classe funcional (10,9 ms x 21,4 ms, p=0,046). Identificamos, também, que o valor do TAV Interventricular que demonstrou melhor acurácia na identificação dos não respondedores foi quando menor do que $20 \mathrm{~ms}$ (sensibilidade: $82 \%$, especificidade de $68 \%$, valor preditivo positivo de $39 \%$ e valor preditivo negativo de $94 \%$, RR: 2,6 [1,5-4,3], $\mathrm{p}=0,005)$. Estes achados valorizam a importância do TAV Interventricular (TAV Inter-Regional VE-VD), durante a estimulação biventricular, em especial o elevado valor preditivo negativo. Esta medida poderá ser utilizada para otimizar a programação do intervalo $\mathrm{V}-\mathrm{V}$, após o implante do ressincronizador. 
O segundo parâmetro clínico analisado foi a mortalidade total. Ao longo dos 1.385 dias de acompanhamento, ocorreram 21 óbitos. A análise dos TAV's Global, Regional e Inter-Regional, durante ritmo sinusal e BRE, mostrou que os pacientes que morreram apresentavam um TAV Regional do VD significativamente maior do que os que permaneceram vivos $(57,7 \mathrm{~ms} \times 48,3 \mathrm{~ms}, \mathrm{p}=0,027)$. Além disso, verificamos que, neste mesmo grupo dos óbitos, o TAV Interventricular (TAV InterRegional VE-VD) era significativamente menor em comparação ao dos vivos $(33,9$ ms x 50,4 ms, $p=0,006)$. Com esta informação, podemos fazer mais duas inferências:

A primeira refere-se à importância da integridade do ventrículo direito antes da TRC, pois a deteriorização do VD, evidenciada pelo prolongamento do seu TAV Regional, medido durante ritmo sinusal e BRE, pode ser um marcador de pior evolução (maior mortalidade) após a TRC.

A segunda refere-se à importância da presença da dissincronia interventricular, pois um menor TAV Interventricular (TAV Inter-Regional VE-VD), em ritmo sinusal e BRE, pode significar um menor benefício da TRC, também associado à maior mortalidade.

Ainda sobre o desfecho mortalidade total, submetemos todas as medidas dos tempos de ativação ventricular (Global, Regional e Inter-Regional) e o Delta TAV, além da duração do complexo QRS à análise univariada. Dentre todos os parâmetros, correlacionaram-se significativamente com maior mortalidade o TAV InterRegional VE-VD e o TAV Inter-Regional Septo-VE durante o ritmo sinusal+BRE, a duração do QRS durante a estimulação biventricular e o Delta TAV Global Médio. 
Os parâmetros que apresentaram valor de $\mathrm{p}$ menor ou igual a 0,10 na análise univariada foram considerados para a análise multivariada. Assim, durante o ritmo sinusal e BRE foram considerados para tal análise a duração do complexo QRS, o TAV Inter-Regional VE-VD e o TAV Inter-Regional Septo-VE. Já durante a estimulação biventricular, o único parâmetro selecionado foi a duração do complexo QRS. E, finalmente, ao avaliar a diferença encontrada entre a estimulação biventricular e o ritmo sinusal e BRE, foram considerados o Delta TAV Global Médio e o Delta TAV Regional do Septo. Para tal, foi utilizada a regressão de Cox multivariado e foi evidenciado que as únicas variáveis independentes correlacionadas com a mortalidade foram o Delta TAV Global Médio $(p=0,006)$ e o TAV InterRegional VE-VD $(0,021)$.

Em resumo, a análise da ativação elétrica ventricular, em especial o TAV Regional do ventrículo direito, o TAV Interventricular (VE-VD) e o Delta TAV Global médio, propiciada pelo mapeamento eletrocardiográfico de superfície em indivíduos submetidos à terapia de ressincronização cardíaca, pode auxiliar na identificação daqueles que melhor se beneficiarão do tratamento.

Mais uma vez ressaltamos que os resultados encontrados relacionados aos desfechos clínicos são meramente especulativos, e não fazem parte do objetivo principal do estudo em questão. A finalidade da apresentação dos mesmos foi levantar algumas possibilidades de aplicação clínica com desfechos relevantes e sugerir futuros estudos, com a adequação científica necessária, para a confirmação destes achados. 


\section{Limitações}

Este foi em estudo retrospectivo e, para homogeneizar ao máximo a amostra de pacientes, utilizamos critérios de exclusão bastante rígidos $(40 \%$ dos pacientes não foram incluídos na análise), o que reduziu o número de indivíduos estudados para 55. Ainda assim, sabemos dos eventuais erros de seleção, descritos abaixo. O momento da realização do mapeamento eletrocardiográfico de superfície variou entre 120 a 300 dias após a TRC, em $95 \%$ da amostra, fato este que poderia alterar alguns dos resultados encontrados. Também não obtivemos a informação da localização do implante do eletrodo do ventrículo esquerdo, dado considerado importante para alguns autores. Os pacientes do estudo apresentaram uma diferença de até dez anos na data do implante do ressincronizador (2000 a 2009), e nesse período podem ter ocorrido diferenças no tratamento farmacológico com implicações no remodelamento cardíaco. 
Capítulo VI

Conclusões 
Conclusões:

O Mapeamento Eletrocardiográfico de Superfície possibilitou a caracterização do comportamento da ativação elétrica ventricular de pacientes submetidos à terapia de ressincronização cardíaca, através da análise dos tempos de ativação ventricular:

1. Global:

$\checkmark$ Redução do TAV Global máximo

2. Regional:

$\checkmark$ Aumento do TAV Regional do ventrículo direito

$\checkmark$ Redução do TAV Regional do ventrículo esquerdo

3. Inter-Regional

$\checkmark$ Redução do TAV Inter-Regional VE-VD

$\checkmark$ Redução do TAV Inter-Regional Septo-VE 
Capítulo VII

Anexos 
Anexo A: Características clínicas dos pacientes do estudo.

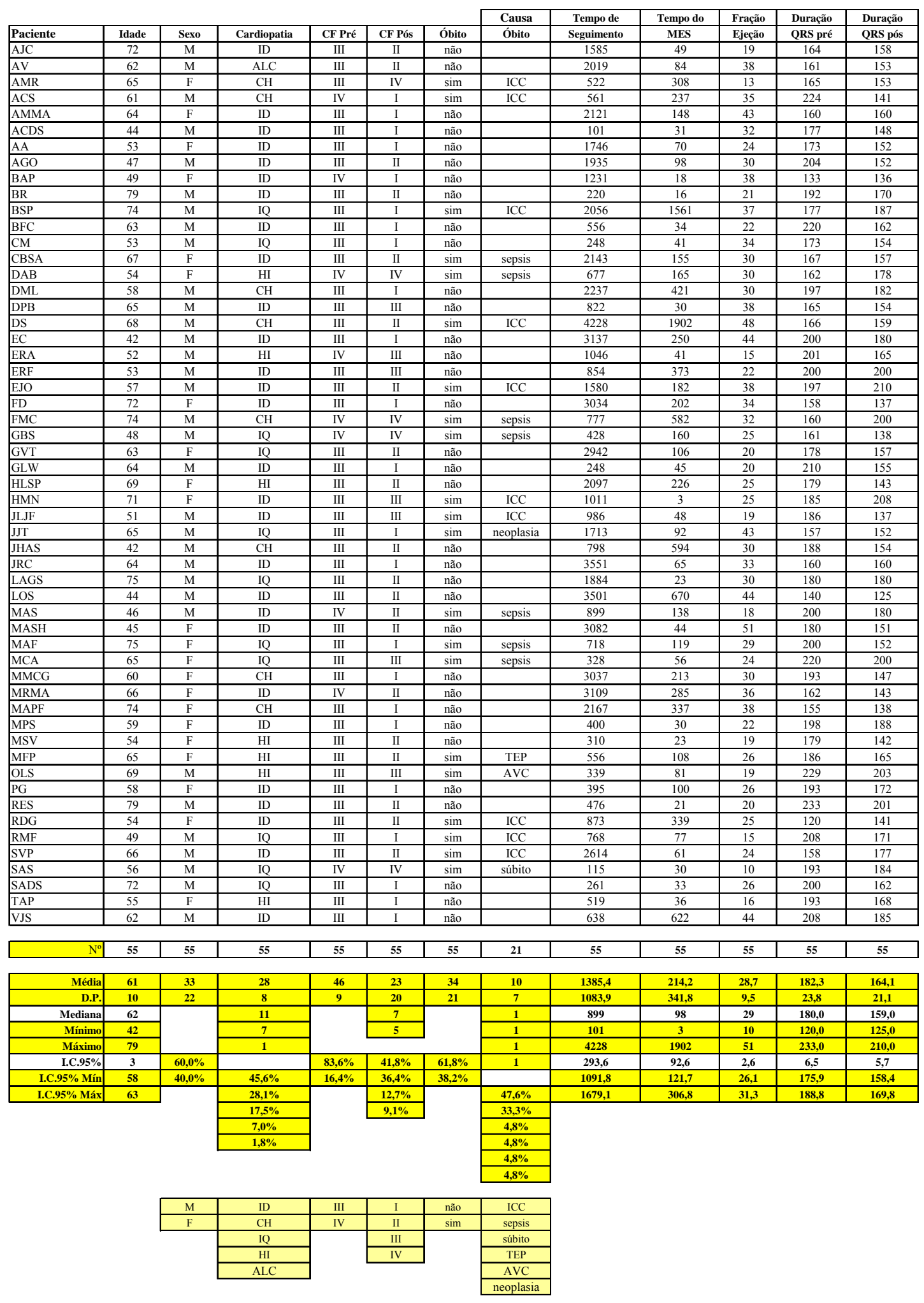


Anexo B: Valores dos tempos de ativação ventricular durante ritmo sinusal + BRE, durante estimulação biventricular e Delta.

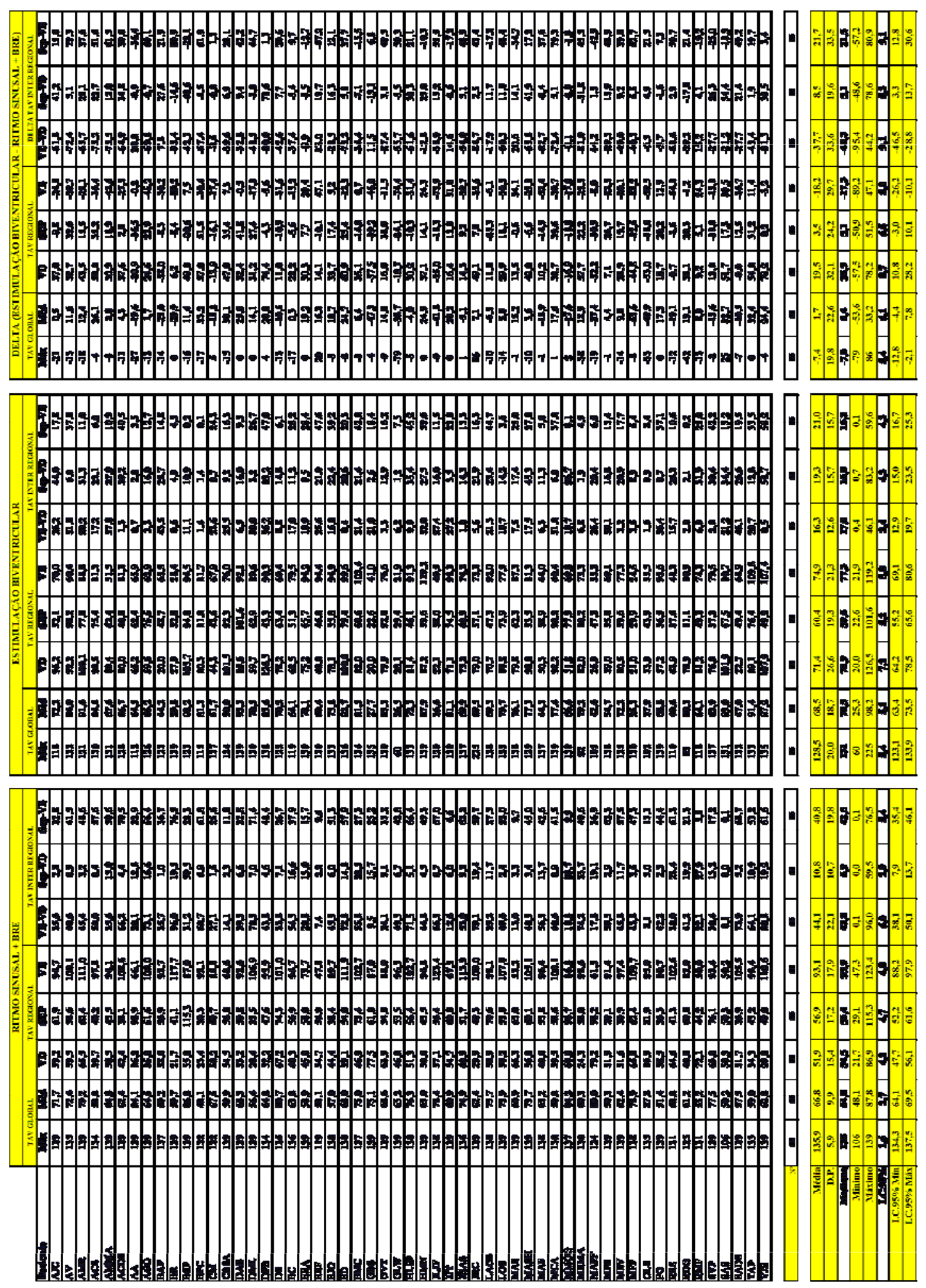


Anexo C: Exemplos de mapeamento eletrocardiográfico de superfície.

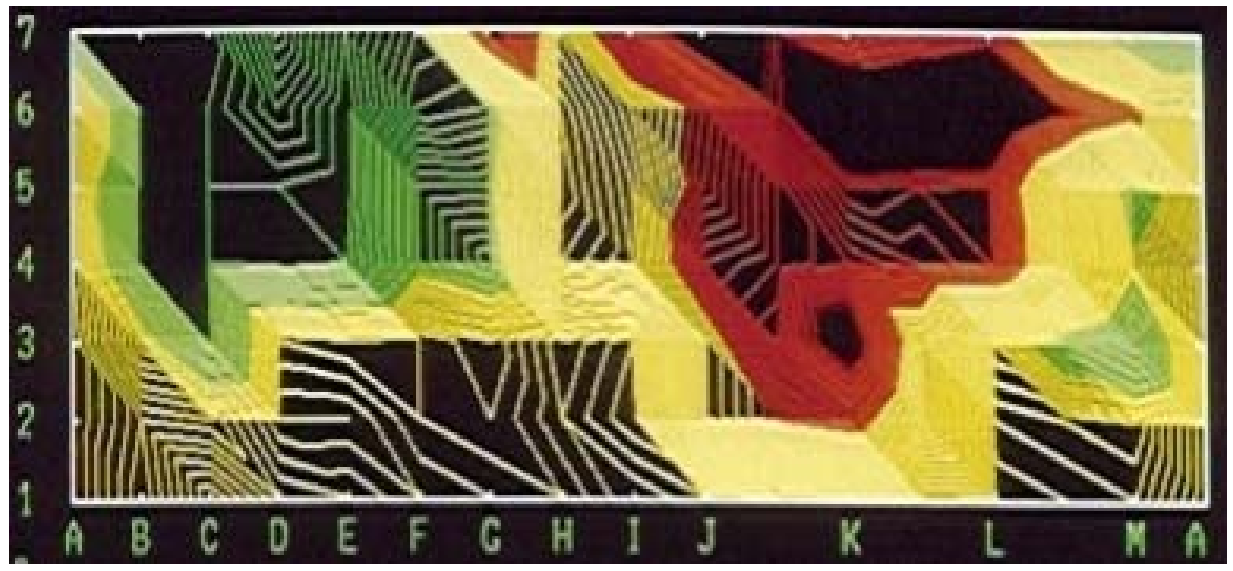

Figura C1: Mapa de linhas isócronas durante ritmo sinusal normal.

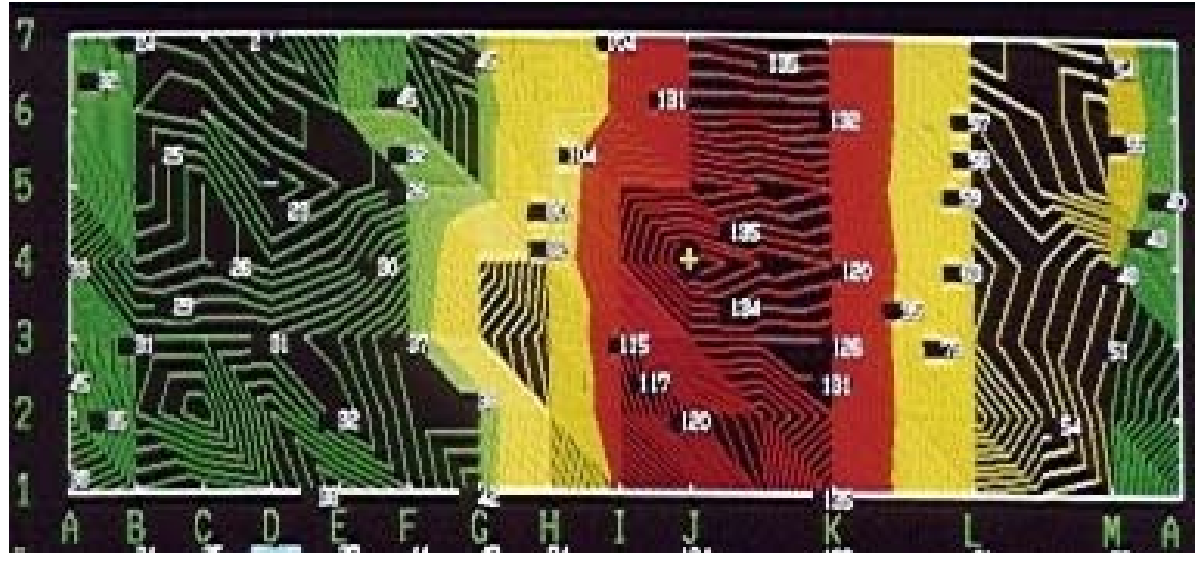

Figura C2: Mapa de linhas isócronas durante ritmo sinusal e BRE.

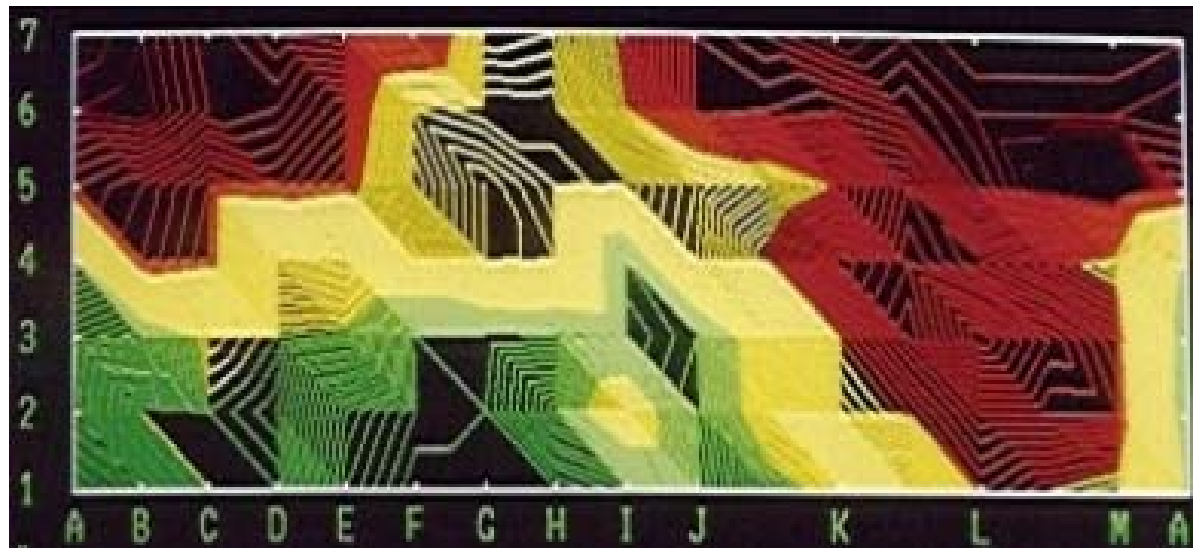

Figura C3: Mapa de linhas isócronas durante estimulação biventricular (TRC). 
Capítulo VIII

Referências 
Referências:

Abraham WT, Fisher WG, Smith AL, Delurgio DB, Leon AR, Loh E et al. Cardiac resynchronization in chronic heart failure. N Engl J Med 2002;346:1845-53.

Abraham WT, Hayes DL. Cardiac resynchronization therapy for heart failure. Circulation 2003;108:2596.

Adelstein EC, Saba S. Usefulness of baseline electrocardiographic QRS complex pattern to predict response to cardiac resynchronization. Am J Cardiol 2009; 103:238-42.

Armstrong PW, Moe GW. Medical advances in the treatment of congestive heart failure. Circulation. 1993;88(6):2941-52.

Auricchio A, Abraham WT. Cardiac resynchronization therapy: current state of the art: cost versus benefit. Circulation 2004a;109:300.

Auricchio A, Fantoni C, Regoli F, Carbucicchio C, Goette A, Geller C, Kloss M, Klein $\mathrm{H}$. Characterization of left ventricular activation in patients with heart failure and left bundle branch block. Circulation. 2004b;109(9):1133-9.

Bakker PF, Meijburg HW, de Vries JW, Mower MM, Thomas AC, Hull ML, et al. Biventricular pacing in end-stage heart failure improves functional capacity and left ventricular function. J Interv Card Electrophysiol. 2000;4(2):395-404. 
Barker WH, Mullooly JP, Getchell W. Changing incidence and survival for heart failure in a well-defined older population, 1970-1974 and 1990-1994. Circulation. 2006;113(6):799-805.

Bax JJ, Ansalone G, Breithardt OA, Derumeaux G, Leclercq C, Schalij MJ, Sogaard P, St John Sutton M, Nihoyannopoulos P. Echocardiographic evaluation of cardiac resynchronization therapy: ready for routine clinical use? A critical appraisal. J Am Coll Cardiol. 2004a;44(1):1-9.

Bax JJ, Bleeker GB, Marwick TH, Molhoek SG, Boersma E, Steendijk P, van der Wall EE, Schalij MJ. Left ventricular dyssynchrony predicts response and prognosis after cardiac resynchronization therapy. J Am Coll Cardiol. 2004b;44(9):1834-40.

Bax JJ, Molhoek SG, van Erven L, Voogd PJ, Somer S, Boersma E et al. Usefulness of myocardial tissue Doppler echocardiography to evaluate left ventricular dyssynchrony before and after biventricular pacing in patients with idiopathic dilated cardiomyopathy. Am J Cardiol 2003;91:94-7.

Bleeker GB, Mollema SA, Holman ER, Van der Veire N, Ypenburg C, Boersma E et al. Left ventricular resynchronization is mandatory for response to cardiac resynchronization therapy: analysis in patients with echocardiographic evidence of left ventricular dyssynchrony at baseline. Circulation 2007;116:1440-8. 
Bortolotto LA, Angelim V, Pastore CA, Silva HB, Moffa P, Pileggi F. Mapeamento eletrocardiográfico de superfície em pacientes com hipertensão maligna. (Resumo) Arq Bras Cardiol 1992;59(supl.II):169

Bradley DJ, Bradley EA, Baughman KL, Berger RD, Calkins H, Goodman SN et al. Cardiac resynchronization and death from progressive heart failure: a metaanalysis of randomized controlled trials. J Am Med Assoc 2003;289:730-40.

Bristow MR, Saxon LA, Boehmer J, Krueger S, Kass DA, De Marco T, Carson P, DiCarlo L, DeMets D, White BG, DeVries DW, Feldman AM; Comparison of medical therapy, pacing, and defibrillation in heart failure (COMPANION) Investigators. Cardiac-resynchronization therapy with or without an implantable defibrillator in advanced chronic heart failure. N Engl J Med. 2004;350(21):214050.

Carvalho FC, Consolim-Colombo FM, Pastore CA, Rubira MC, Menegüetti JC, Krieger EM, Wajngarten M. Acute reduction of ventricular volume decreases QT interval dispersion in elderly subjects with and without heart failure. Am J Physiol Heart Circ Physiol. 2005;288(5):H2171-76.

Cazeau S, Leclercq C, Lavergne T, Walker S, Varma C, Linde C et al. Effects of multisite biventricular pacing in patients with heart failure and intraventricular conduction delay. N Engl J Med 2001;344:873-80.

Chizzola PR, Freitas HF, Caldas MA, da Costa JM, Meneghetti C, Marinho NV, Mansur AJ, Ramires JA, Bocchi EA. Efeitos do carvedilol na insuficiência 
cardíaca por cardiomiopatia dilatada. Resultado de estudo duplo-cego, randômico, com grupo placebo-controle (Estudo CARIBE). [Effects of carvedilol in heart failure due to dilated cardiomyopathy. Results of a double-blind randomized placebo-controlled study (CARIBE study)]. Arq Bras Cardiol. 2000;74(3):233-42.

Chung ES, Leon AR, Tavazzi L, Sun JP, Nihoyannopoulos P, Merlino J et al. Results of the predictors of response to CRT (PROSPECT) trial. Circulation 2008;117:2608-16.

Cleland JG, Daubert JC, Erdmann E, Freemantle N, Gras D, Kappenberger L, Tavazzi L. Cardiac Resynchronization-Heart Failure (CARE-HF) Study Investigators. The effect of cardiac resynchronization on morbidity and mortality in heart failure. N Engl J Med. 2005;352(15):1539-49.

Daubert JC, Leclercq C, Donal E, Mabo P. Cardiac resynchronisation therapy in heart failure: current status. Heart Fail Rev 2006;11:147-54.

Dickstein K, Bogale N, Priori S, Auricchio A, Cleland JG, Gitt A et al. The European cardiac resynchronization therapy survey. Eur Heart J 2009;30:2450-60.

Donal E, Leclercq C, Linde C, Daubert JC. Effects of cardiac resynchronization therapy on disease progression in chronic heart failure. Eur Heart J 2006;27: $1018-25$.

Eterno FT, Oliveira Jr MT, Barretto ACP. Diuréticos melhoram a capacidade funcional em pacientes com insuficiência cardíaca congestiva. Arq Bras Cardiol 1998;70(5):315-20. 
Fantoni C, Kawabata M, Massaro R, Regoli F, Raffa S, Arora V, Salerno-Uriarte JA, Klein HU, Auricchio A. Right and left ventricular activation sequence in patients with heart failure and right bundle branch block: a detailed analysis using threedimensional non-fluoroscopic electroanatomic mapping system. J Cardiovasc Electrophysiol. 2005;16(2):112-9.

Ferreira Filho SR, Hatab SA, Benchimol C, Nascimento LOT, Saragoça MA. Captopril no tratamento de pacientes com insuficiência cardíaca congestiva. Avaliação cicloergométrica. Arq Bras Cardiol 1992;59(6):487-91.

Ferreira SM, Guimarães GV, Cruz FD, Issa VS, Bacal F, Sousa GE, Chizzola PR, Mangini S, Bocchi EA. Anemia and renal failure as predictors of risk in a mainly non-ischemic heart failure population. Int J Cardiol. 2010;141(2):198-200.

Foody JM, Farrell MH, Krumholz HM. beta-Blocker therapy in heart failure: scientific review. JAMA. 2002;287(7):883-9.

Garg R, Yusuf S. Overview of randomized trials of angiotensin-converting enzyme inhibitors on mortality and morbidity in patients with heart failure. Collaborative Group on ACE Inhibitor Trials. JAMA. 1995;273(18):1450-6.

Gervais R, Leclercq C, Shankar A, Jacobs S, Eiskjaer H, Johannessen A et al. Surface electrocardiogram to predict outcome in candidates for cardiac resynchronization therapy: a sub-analysis of the CARE-HF trial. Eur J Heart Fail 2009;11:699-705. 
Gun C, Piegas LS, Bianco ACM, Freire RBP, Ramos RF, Timerman A. Valor do Uso da milrinona no tratamento das crises de agudização em portadores de insuficiência cardíaca congestiva. Arq Bras Cardiol 1995;65(3):255-8.

Hawkins NM, Petrie MC, MacDonald MR, Hogg KJ, McMurray JJ. Selecting patients for cardiac resynchronization therapy: electrical or mechanical dyssynchrony? Eur Heart J 2006;27:1270-81.

Ho KK, Anderson KM, Kannel WB, Grossman W, Levy D. Survival after the onset of congestive heart failure in Framingham Heart Study subjects. Circulation. 1993a;88(1):107-15.

Ho KK, Pinsky JL, Kannel WB, Levy D. The epidemiology of heart failure: the Framingham Study. J Am Coll Cardiol. 1993b;22(4 Suppl A):6A-13A.

Hunt SA; American College of Cardiology; American Heart Association Task Force on Practice Guidelines (Writing Committee to Update the 2001 Guidelines for the Evaluation and Management of Heart Failure). ACC/AHA 2005 guideline update for the diagnosis and management of chronic heart failure in the adult: a report of the American College of Cardiology/American Heart Association Task Force on Practice Guidelines (Writing Committee to Update the 2001 Guidelines for the Evaluation and Management of Heart Failure). J Am Coll Cardiol. 2005;46(6):e1-82. 
Huang Y, Wu W, Cao Y, Qu N. All cause mortality of cardiac resynchronization therapy with implantable cardioverter defibrillator: A meta-analysis of randomized controlled trials. Int J Cardiol. 2010;145:413-417.

Issa VS, Amaral AF, Cruz FD, Ferreira SM, Guimarães GV, Chizzola PR, Souza GE, Bacal F, Bocchi EA. Beta-blocker therapy and mortality of patients with Chagas cardiomyopathy: a subanalysis of the REMADHE prospective trial. Circ Heart Fail. 2010;3(1):82-8.

Jarcho JA. Resynchronizing ventricular contraction in heart failure. N Engl J Med 2005;352:1594.

Kannel WB. Incidence and epidemiology of heart failure. Heart Fail Rev. 2000;5(2):167-73.

Kannel WB, Belanger AJ. Epidemiology of heart failure. Am Heart J. 1991;121(3 Pt 1):951-7.

Kashani A, Barold SS. Significance of QRS complex duration in patients with heart failure. J Am Coll Cardiol 2005;46:2183-92.

Leclercq C, Hare JM. Ventricular resynchronization: current state of the art. Circulation 2004;109:296.

Leclercq C, Kass DA. Retiming the failing heart: principles and current clinical status of cardiac resynchronization. J Am Coll Cardiol 2002;39:194. 
Lecoq G, Leclercq C, Leray E, Crocq C, Alonso C, de PC et al. Clinical and electrocardiographic predictors of a positive response to cardiac resynchronization therapy in advanced heart failure. Eur Heart J 2005;26:1094100.

Lemos Júnior HP, Atallah AN. Cardiac resynchronization therapy in patients with heart failure: systematic review - Terapia de ressincronização cardíaca em pacientes com insuficiência cardíaca: revisão sistemática. São Paulo Med J. 2009;127(1):40-45.

Levy D, Kenchaiah S, Larson MG, Benjamin EJ, Kupka MJ, Ho KK, Murabito JM, Vasan RS. Long-term trends in the incidence of and survival with heart failure. $\mathrm{N}$ Engl J Med. 2002;347(18):1397-402.

Martinelli Filho M, Zimerman LI, Lorga AM, Vasconcelos JTM, Rassi A Jr. Guidelines for implantable electronic cardiac devices of the brazilian society of cardiology. Arq Bras Cardiol 2007;89(6):e210-38.

McAlister FA, Ezekowitz J, Hooton N, et al. Cardiac resynchronization therapy for patients with left ventricular systolic dysfunction: a systemic review. JAMA 2007;297:2502.

Medvegy M, Duray G, Pinter A, Preda I. Body surface potential mapping: Historical background, present possibilities, diagnostic challenges. Ann Noninvasive Electrocardiol 2002;7:139-51. 
Merkely B, Roka A, Kutyifa V, Boersma L, Leenhardt A, Lubinski A, et al. Tracing the European course of cardiac resynchronization therapy from 2006 to 2008. Europace 2010;12(5):692-701.

Moffa PJ, Pastore CA, Grupi CJ, Morais AP. Eletrocardiografia - Início, Evolução, Situação Atual (subtítulo "Aspectos técnicos e aplicações clínicas do mapeamento eletrocardiográfico computadorizado de superfície - body surface mapping). In: Sousa A.G.M.R.; Mansur A. J. (eds). SOCESP CARDIOLOGIA Atualização e Reciclagem. São Paulo: Atheneu, 1994; (Cap. 2) p.12-27.

Molhoek SG, Van Erven L, Bootsma M, Steendijk P, Van Der Wall EE, Schalij MJ. QRS duration and shortening to predict clinical response to cardiac resynchronization therapy in patients with end-stage heart failure. Pacing Clin Electrophysiol 2004;27:308-13.

Moss AJ, Hall WJ, Cannom DS, Klein H, Brown MW, Daubert JP et al., Estes NAM3. Cardiac-resynchronization therapy for the prevention of heart-failure events. N Engl J Med 2009;361:1329-38.

Murphy RT, Sigurdsson G, Mulamalla S, et al. Tissue synchronization imaging and optimal left ventricular pacing site in cardiac resynchronization therapy. Am J Cardiol 2006;97:1615.

Pastore CA. Mapeamento Eletrocardiográfico de Superfície. In: Antonio Américo Friedmann, José Grindler (eds). Eletrocardiologia Básica. São Paulo: Sarvier Editora de Livros Médicos Ltda., 2000; (v.I, Cap. 13) p. 129-34. 
Pastore CA. Mapeamento Eletrocardiográfico de Superfície ("Body Surface Potential Mapping"). In: Paulo Jorge Moffa, Paulo César R. Sanches (coord.). José Antonio F. Ramires, Sérgio Almeida de Oliveira (eds). Eletrocardiograma Normal e Patológico. São Paulo: Editora Roca, 2001; (v.l, Cap. 33) p. 869-80.

Pastore CA. Mapeamento eletrocardiográfico de superfície. In: Friedmann Antonio Américo (ed). Eletrocardiograma em 7 aulas; temas avançados e outros métodos. Barueri, SP: Manole, 2011. (Cap. 28) p.299-309.

Pastore CA, Arcêncio S R, Tobias NMMO, Kaiser E, Martinelli Filho M, Moreira, Luis Felipe P, Stolf NAG, Bocchi EA, Ramires JAF. QT interval dispersion analysis in patients undergoing left partial ventriculectomy (Batista operation). Annals of Noninvasive Electrocardiology 2004;9:375-82.

Pastore CA, Moffa PJ. Aspectos técnicos e aplicações clínicas do mapeamento eletrocardiográfico de superfície (Body Surface Mapping). Arq Bras Cardiol $1992 ; 58(5): 391-7$

Pastore CA, Moffa PJ. Body surface potential mapping to identify localization of ventricular insertion of accessory pathways in Wolff-Parkinson-White syndrome. In Electrocardiology 93 (XXth International Congress on Electrocardiology). P.W. Macfarlane, P. Rautaharju (eds ); Singapore: World Scientific Publishing Co., 1993; p.161-4 (Proceedings)

Pastore CA, Moffa PJ, Tobias NM, Moraes AP, Kaiser E, Bellotti GM, Pileggi F. Diagnóstico do infarto inferior antigo pelo mapeamento eletrocardiográfico de 
superfície comparado com o vetorcardiograma. [Resumo] Arq Bras Cardiol 1991;57(supl.C):C83. (Anais)

Pastore CA, Moffa PJ, Tobias NM, Moraes AG, Kaiser E, Cuoco MA, Mansur A, Granado G, Sanchez MDC, Bellotti G, Pileggi F. Análise do bloqueio do ramo esquerdo pelo mapeamento eletrocardiográfico de superfície. Comparação com os achados eletro-vetorcardiográficos. Arq Bras Cardiol. 1996;66(5):253-6.

Pastore CA, Moffa, P. J.; Tobias, N.; Moraes, A. P.; Kaiser, E.; Mansur, A.; Favarato, D.; Ramires JAF, Bellotti, G.; Pileggi, F. Body surface mapping in the anterior ventricular aneurysm after myocardial infarction. In: J. Liebman (ed.) Electrocardiology 96 - From the Cell to the Body Surface (XXIII International Congress on Electrocardiology). Singapore: World Scientific Publishing Co. Pte. Ltd., 1997; p.503-6. (Proceedings)

Pastore CA, Samesima N, Tobias NMMO, Kaiser E, Pedrosa A, Martinelli Filho M, Arcêncio SR, Ramires JF. Dispersão do intervalo QT na distrofia muscular progressiva: análise pelo mapeamento eletrocardiográfico de superfície. [Resumo] Arq Bras Cardiol 2002a;79(supl.III):28. (Anais)

Pastore CA, Tobias NM, Kaiser E, Samesima N, Felicioni S, Martinelli Filho M, Pedrosa A, Nishioka SAD, Siqueira S, Ramires JAF. Can body surface potential mapping confirm cardiac re-synchronization in patients with heart failure + left bundle branch block, treated with biventricular pacing? In: Pastore CA (ed). Electrocardiology 2001 (XXVIII International Congress on Electrocardiology) São Paulo: Atheneu Editora Ltda., 2002b; p.59-66. (Proceedings) 
Pastore CA, Tobias NM, Moffa PJ, Chacra AP, Kalil R, Albuquerque C, Tranchesi B, Bellotti G, Pileggi F. Body surface mapping in the diagnosis of right ventricular infarction. In: S. Yasui, J.A. Abildskov, K. Yamada, K. Harumi (eds.). Advances in Body Surface Mapping and High Resolution ECG. Nagoya, Japan: Life Medicom Co. Ltd., 1995; p.77-81

Pastore CA, Tobias N, Samesima N, Filho MM, Pedrosa A, Nishioka S, Douglas RA, Moreira LF, Ramires JF. Body surface potential mapping investigating the ventricular activation patterns in the cardiac resynchronization of patients with left bundle-branch block and heart failure. J Electrocardiol. 2006;39(1):93-102.

Pastore CA, Tobias N, Samesima N, Martinelli Filho M, Pedrosa A, Nishioka S, Douglas RA, Moreira LF, Ramires JF. Ventricular electrical activation in cardiac resynchronization as characterized by body surface potential mapping. Arq Bras Cardiol. 2007;88(3):251-7.

Peichl P, Kautzner J, Cihak R, Bytesnik J. The spectrum of inter- and intraventricular conduction abnormalities in patients eligible for cardiac resynchronization therapy. Pacing Clin Electrophysiol 2004;27:1105-12.

Piccini JP, Hernandez AF, Dai D, Thomas KL, Lewis WR, Yancy CW et al. Use of cardiac resynchronization therapy in patients hospitalized with heart failure. Circulation 2008;118:926-33. 
Pitzalis MV, lacoviello M, Romito R, Massari F, Rizzon B, Luzzi G et al. Cardiac resynchronization therapy tailored by echocardiographic evaluation of ventricular asynchrony. J Am Coll Cardiol 2002;40:1615-22.

Pratola C, Notarstefano P, Toselli T, Artale P, Squasi P, Baldo E, et al. Noncontact mapping of left ventricle during CRT implant. Pacing Clin Electrophysiol. 2010;33(1):74-84.

Reynolds MR, Joventino LP, Josephson ME. Relationship of baseline electrocardiographic characteristics with the response to cardiac resynchronization therapy for heart failure. Pacing Clin Electrophysiol 2004;27:1513-8.

Rivero-Ayerza M, Theuns DA, Garcia-Garcia HM, et al. Effects of cardiac resynchronization therapy on overall mortality and mode of death: a metaanalysis of randomized controlled trials. Eur Heart J 2006;27:2682.

Rodriguez LM, Timmermans C, Nabar A, Beatty G, Wellens HJ. Variable patterns of septal activation in patients with left bundle branch block and heart failure. J Cardiovasc Electrophysiol. 2003 Feb;14(2):135-41.

Roger VL, Weston SA, Redfield MM, Hellermann-Homan JP, Killian J, Yawn BP, Jacobsen SJ. Trends in heart failure incidence and survival in a community-based population. JAMA. 2004;292(3):344-50.

Rossi A, Rossi G, Piacenti M, Startari U, Panchetti L, Morales MA. The current role of cardiac resynchronization therapy in reduncing mortality and 
hospitalization in heart failure patients: a meta-analysis from clinical trials. Heart Vessels. 2008;23:217-223.

Samesima N, Pastore CA, Tobias N, Kaiser E, Pereira A, Darrieux F, Scanavacca M, Sosa E. A new method to identify brugada syndrome in asymptomatic patients with normal 12-lead ECG. NASPE 24th Annual Scientific Sessions, Washington DC, EUA. [Resumo] PACE - Pacing and Clinical Electrophysiology 2003;26(4),Part II:1113. (Proceedings)

Sassone B, Gabrieli L, Saccà S, Boggian G, Fusco A, Pratola C, et al. Value of right ventricular-left ventricular interlead electrical delay to predict reverse remodelling in cardiac resynchronization therapy: the INTER-V pilot study. Europace 2010;12(1):78-83.

Saxon LA, Ellenbogen KA. Resynchronization therapy for the treatment of heart failure. Circulation. 2003;108(9):1044-8.

Silva CES, Barretto ACP. Avaliação ecocardiográfica da terapia de ressincronização cardíaca. Arq Bras Cardiol 2005;84(6):503-7.

Singh JP, Fan D, Heist KE, Alabiad CR, Taub C, Reddy V et al. Left ventricular lead electrical delay predicts response to cardiac resynchronization therapy. Heart Rhythm 2006;3:1285-92.

St John Sutton MG, Plappert T, Abraham WT, Smith AL, DeLurgio DB, Leon AR et al. Effect of cardiac resynchronization therapy on left ventricular size and function in chronic heart failure. Circulation 2003;107:1985-90. 
Stellbrink C, Breithardt OA, Franke A, Sack S, Bakker P, Auricchio A et al. Impact of cardiac resynchronization therapy using hemodynamically optimized pacing on left ventricular remodeling in patients with congestive heart failure and ventricular conduction disturbances. J Am Coll Cardiol 2001;38:1957-65.

Szlejf C, Rays J, Gebara OCE, Vieira NW, Pierri H, Nussbacher A, Serro-Azul JB, Samesima N, Pastore CA, Wajngarten M. Relação entre os comportamentos das dispersões da onda P e do intervalo QT em idosos com insuficiência cardíaca. [Resumo] Arq Bras Cardiol 2002;79(5):494-6. (Anais)

van Gelder BM, Meijer A, Bracke FA. The optimized V-V interval determined by interventricular conduction times versus invasive measurement by LVdP/dtMAX. J Cardiovasc Electrophysiol. 2008;19(9):939-44.

Vardas PE, Auricchio A, Blanc JJ, Daubert JC, Drexler H, Ector H. Guidelines for cardiac pacing and cardiac resynchronization therapy: The Task Force for Cardiac Pacing and Cardiac Resynchronization Therapy of the European Society of Cardiology. Developed in Collaboration with the European Heart Rhythm Association. Eur Heart J 2007;28(18):2256-95.

Varma N, Jia P, Rudy Y. Electrocardiographic imaging of patients with heart failure with left bundle branch block and response to cardiac resynchronization therapy. J Electrocardiol. 2007;40(6 Suppl):S174-8.

Villacorta H, Mesquita ET. Fatores prognósticos em portadores de insuficiência cardíaca congestiva. Arq Bras Cardiol 1999;72(3):343-52. 
Ypenburg C, van Bommel RJ, Borleffs CJ, Bleeker GB, Boersma E, Schalij MJ et al. Long-term prognosis after cardiac resynchronization therapy is related to the extent of left ventricular reverse remodeling at midterm follow-up. J Am Coll Cardiol 2009;53:483-90.

Yu CM, Bleeker GB, Fung JWH, Schalij MJ, Zhang Q, van der Wall EE et al. Left ventricular reverse remodeling but not clinical improvement predicts long-term survival after cardiac resynchronization therapy. Circulation 2005;112:1580-6.

Yu CM, Fung WH, Lin $H$, Zhang $Q$, Sanderson JE, Lau CP. Predictors of left ventricular reverse remodeling after cardiac resynchronization therapy for heart failure secondary to idiopathic dilated or ischemic cardiomyopathy. Am J Cardiol 2003;91:684-8. 